\title{
Formulation, development, and optimization of a novel octyldodecanol-based nanoemulsion for transdermal delivery of ceramide IIIB
}

This article was published in the following Dove Press journal:

International Journal of Nanomedicine

21 July 2017

Number of times this article has been viewed

\author{
Runping Su' \\ Li Yang ${ }^{2}$ \\ Yue Wang' \\ Shanshan Yu' \\ Yu Guo' \\ Jiayu Deng' \\ Qianqian Zhao' \\ Xiangqun Jin' \\ 'Department of Pharmaceutics, \\ School of Pharmacy, ${ }^{2}$ Key Laboratory \\ of Zoonosis Research, Ministry of \\ Education, Institute of Zoonosis, \\ College of Veterinary Medicine, Jilin \\ University, Changchun, China
}

\begin{abstract}
This research aimed to develop and optimize a nanoemulsion-based formulation containing ceramide IIIB using phase-inversion composition for transdermal delivery. The effects of ethanol, propylene glycol (PG), and glycerol in octyldodecanol and Tween 80 systems on the size of the nanoemulsion region in the phase diagrams were investigated using water titration. Subsequently, ceramide IIIB loading was kept constant $(0.05 \mathrm{wt} \%)$, and the proposed formulation and conditions were optimized via preliminary screening and experimental design. Factors such as octyldodecanol/(Tween 80:glycerol) weight ratio, water content, temperature, addition rate, and mixing rate were investigated in the preliminary screening experiment. Response surface methodology was employed to study the effect of water content $(30 \%-70 \%$, w/w), mixing rate $(400-720 \mathrm{rpm})$, temperature $\left(20^{\circ} \mathrm{C}-60^{\circ} \mathrm{C}\right)$, and addition rate $(0.3-1.8 \mathrm{~mL} / \mathrm{min})$ on droplet size and polydispersity index. The mathematical model showed that the optimum formulation and conditions for preparation of ceramide IIIB nanoemulsion with desirable criteria were a temperature of $41.49^{\circ} \mathrm{C}$, addition rate of $1.74 \mathrm{~mL} / \mathrm{min}$, water content of $55.08 \mathrm{wt} \%$, and mixing rate of $720 \mathrm{rpm}$. Under optimum formulation conditions, the corresponding predicted response values for droplet size and polydispersity index were $15.51 \mathrm{~nm}$ and 0.12 , respectively, which showed excellent agreement with the actual values (15.8 $\mathrm{nm}$ and 0.108 , respectively), with no significant $(P>0.05)$ differences.
\end{abstract}

Keywords: response surface methodology, nanoemulsions, optimization, particle size, polydispersity index

\section{Introduction}

Environmental changes and improper skin care affect the conditions of normal skin and may trigger various cutaneous disorders, such as common dermatitis, and may decline the barrier function of the skin. ${ }^{1}$ This investigation focused on ceramide IIIB, which is known to improve water content and smoothen human skin upon topical application. $^{2}$

Ceramide IIIB supports renewal of the skin's natural protective layer and forms an effective barrier against moisture loss. Therefore, this molecule, identical to human skin, is particularly suitable for long-term protection and repair of sensitive and dry skin. ${ }^{3}$ At present, for ceramide IIIB to be active, at least $0.05 \mathrm{wt} \%$ of it should be present in cosmetic products. However, its application in cosmetics and pharmaceuticals is difficult, owing to its low solubility. Therefore, a carrier should be developed for incorporating ceramide IIIB for application in cosmetics and pharmaceuticals with the following characteristics: it should not produce skin irritation, it should dissolve ceramide IIIB well, and it should have good skin permeability and high bioavailability.
Correspondence: Xiangqun jin Department of Pharmaceutics, School of Pharmacy, jilin University, I266 Fujin Road, Changchun I3002I, China

Tel $+86|8843| 0565 \mid$

Fax $+8643|856| 9662$

Email jinxq@jlu.edu.cn 
A nanoemulsion containing ceramide IIIB has been prepared by high-energy emulsification methods. ${ }^{3}$ These highenergy methods require complicated equipments and high energy for industrial scale production compared to low-energy methods. Low-energy methods are advantageous because optimum establishment of the phase diagram generates the smallest nanoemulsion and low-energy methods makes scaling up easy. ${ }^{4}$ These methods include phase-inversion temperature, phase-inversion composition (PIC), and spontaneous emulsification. Organic solvents are generally not recommended in most cases for use in the field of cosmetics. ${ }^{4}$ It is relevant to point out that use of phase-inversion temperature is not suitable for thermosensitive active compounds. Therefore, we prepared an oil-in-water $(\mathrm{O} / \mathrm{W})$ nanoemulsion using water titration. The PIC method has great potential for scaling up applications because of its ease of formation and relatively low energy costs. ${ }^{5}$ Phase transition is produced by stepwise addition of water to a mixture of the surfactant and oil for the formation of $\mathrm{O} / \mathrm{W}$ nanoemulsions. ${ }^{6}$

Emulsifiers are common constituents of most topical medicaments and cosmetics because they enable the solubilization of otherwise-insoluble compounds. ${ }^{7}$ TW80 is an odorless and tasteless nonionic surfactant with a hydrophiliclipophilic balance of $15 \pm 1$. Due to its surface activity and chemical structure, polysorbate 80 is capable of reducing the interfacial tension of the system. ${ }^{8}$ It is often used as a solubilizer and wetting agent. ${ }^{9}$ The skin-friendliness of the developed nanoemulsion systems might be impaired with increasing TW80 content. Therefore, we need to add a cosurfactant to reduce the concentration of TW80.

To prepare a nanoemulsion the following aspects should be considered. It is generally believed that nanoemulsions of particle size $1-100 \mathrm{~nm}$ possess a large interfacial area, ${ }^{10,11}$ which helps to overcome the epidermal barrier that might favor skin permeation of active substances. Nanoemulsions have notable adhesive properties on the skin surface upon administration, because the water in the formulation evaporates, leaving behind a film of oil droplets. Due to capillary forces of the nanosize pores, fusion and formation of a film is promoted, and pressure can reinforce this effect. This leads to increased skin hydration, which may promote the absorption of topically applied drugs or cosmetics. ${ }^{12}$ The very small droplet size greatly reduces the gravitational force, ${ }^{13}$ and Brownian motion largely prevents gravitationally driven sedimentation or creaming. ${ }^{6,10,14}$ The transparent nature of $\mathrm{O} / \mathrm{W}$ nanoemulsions, their good fluidity, and the absence of any thickeners give them a pleasant aesthetic character and skin feel. ${ }^{13}$

Nanoemulsions improve the topical efficacy of active ingredients due to their small particle size. The formulation and process variables influence the particle size and polydispersity index (PDI) in different manners when interactions occur among the different variables. Response surface methodology (RSM) is a powerful and effective statistical tool for multivariate analysis of the relationships between independent variables and response variables. ${ }^{15,16}$

In this paper, an optimization procedure involving a preliminary screening experiment and RSM was performed. We aimed to optimize the processing conditions and formulation compositions for the preparation of ceramide IIIB-loaded nanoemulsions with the smallest particle size and lowest PDI values by RSM.

\section{Materials and methods Materials}

On the basis of the formulation elaborated, stable nanoemulsions were obtained. Tween 80 (polysorbate 80 ) was used as the emulsifier. Additionally, short-chain alcohols (ethanol, glycerol, PG) were tested as cosurfactants. The cosmetic oil Tegosoft G20 (octyldodecanol) and Tween 80 were obtained from Evonik (Essen, Germany), which also kindly provided ceramide IIIB. Ethanol was purchased from Merck (Darmstadt, Germany). PG (propylene glycol) was bought from SKC (Seoul, South Korea). Glycerol was procured from KLK Emmerich $\mathrm{GmbH}$, (Emmerich am Rhein, Germany). All ingredients used in the formulation are characterized in Table 1. All ingredients used were of pharmaceutical, food, or cosmetic grade. Distilled water was used throughout the study. Structures of Tween 80, ceramide IIIB, and octyldodecanol are shown in Figure 1.

\section{Construction of phase diagram}

All components were weighted and mixed under magnetic stirring. Compositions are expressed in $\mathrm{wt} \%$ ratio between components and also as w:w ratio. Phase diagrams were constructed using the aqueous titration method at ambient temperature. Figures S1 and S2 depict the phase-diagram structure, which was used to identify the maximum region of stable emulsion for formulation development.

Initially, Tween 80 was combined with three types of solubilizers as cosurfactants tested in the present investigation:

Table I Screening of ingredient contents

\begin{tabular}{ll}
\hline Compound content & Wt\% \\
\hline Ceramide IIIB & 0.05 \\
Tegosoft G20 & $3,4, \mathbf{5}, 6,7$ \\
Tween 80 & $13.5,18,22.5,27,31.5$ \\
Glycerol & $13.5,18,22.5,27,31.5$ \\
Water & $30,40,50,60,70$ \\
\hline
\end{tabular}

Note: Numbers in bold indicate compound content kept constant, while the others were varied. 


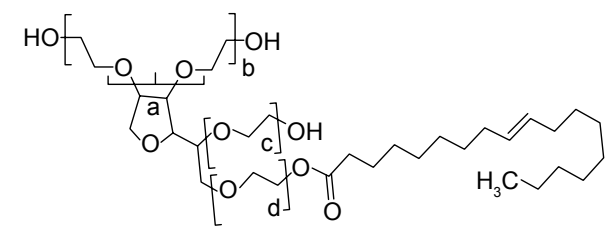

$a+b+c+d=20 ;$ polysorbate 80

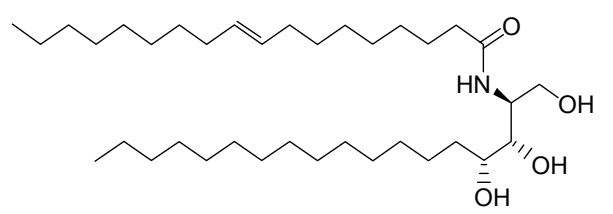

Ceramide IIIB

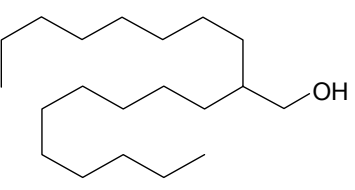

Octyldodecanol

Figure I Chemical structures of Tween 80, ceramide IIIB, and octyldodecanol used in this study (ChemDraw ${ }^{\circledR}$, CambridgeSoft).

PG, glycerol, and ethanol. At a fixed surfactant:cosurfactant $\left(\mathrm{S}_{\text {mix }}\right)$ ratio of 1:1, oil and $\mathrm{S}_{\text {mix }}$ ratio were mixed well in different mass ratios from 1:9 to 9:1 under magnetic stirring. The nanoemulsion phase was identified as the region in the phase diagram where clear, easily flowable, and transparent formulations were obtained based on visual observation. Cosurfactants that attained the maximum nanoemulsion region were selected for formulation development. ${ }^{17}$

Phase diagrams were plotted using Tegosoft G20 as the oil phase and Tween 80 and glycerol as the surfactant and cosurfactant, respectively. Tween 80 was blended with glycerol at weight ratios of 1:3, 1:2, 1:1, 1:0, 2:1, and 3:1. These $\mathrm{S}_{\text {mix }}$ ratios were chosen in raising the concentration of the surfactant with respect to the cosurfactant and decreasing the concentration of the cosurfactant with respect to the surfactant for meticulous research of the phase diagrams. Titration of water was conducted with various combinations in different weight ratios of oil to $\mathrm{S}_{\text {mix }}(1: 9,1: 8,1: 7,1: 6,1: 5$, 1:4, 1:3, 1:2, 1:1, 6:4, 7:3, and 9:1). Stepwise addition of water was carried out on each mass ratio of oil and $\mathrm{S}_{\text {mix }}$, and visual observations were made for transparent and singlephase mixtures. When an opaque fluid system was observed, the amounts of water added were recorded to complete the phase diagrams. Three axes of the pseudo-three-component phase diagram represented water, Tegosoft G20, and a mixture of surfactant and cosurfactant at a fixed weight ratio, respectively.

\section{Preparation of ceramide IIIB-loaded nanoemulsions}

$\mathrm{O} / \mathrm{W}$ nanoemulsions were formulated using Tegosoft G20 as the dispersed oil phase and Tween 80 and glycerol as the surfactant and cosurfactant, respectively. The results of pseudoternary phase analysis showed that the combined use of surfactant-cosurfactant (Tween 80-glycerol, 1:1 w:w) enlarged the self-emulsifying area. Oil was blended with surfactant and cosurfactant at weight ratios of 1:9, 2:8, and 3:7. Ceramide IIIB was dissolved in Eutanol $\mathrm{G}$ above $100^{\circ} \mathrm{C}$ and then cooled to a specified temperature. TW80 and glycerol were dissolved in the oil phase. Nanoemulsions were prepared by continuous addition of distilled water to mixtures of Eutanol G, Tween 80, and glycerol (Table 1). Each formulation was prepared by heating the mixture at different temperatures ranging from $20^{\circ} \mathrm{C}$ to $60^{\circ} \mathrm{C}$ in a thermostatic bath (Julabo F25-ME) under constant magnetic stirring (400-720 rpm) and at an addition rate of $0.3-1.8 \mathrm{~mL} / \mathrm{min}$. Then, each formulation was stirred continuously for $30 \mathrm{~min}$. Nanoemulsions were prepared by varying the emulsification parameters (Table 2), in order to screen these parameters with respect to achieving small emulsions with close size distributions for high physical stability. In fast-screening studies, the influence of different variables on emulsion properties was checked. Three variables were considered: emulsification temperature, addition rate, and mixing rate. The emulsions were sampled and evaluated in terms of particle size and PDI.

\section{Experimental design}

After the preliminary determination of desirable nanoemulsion region, a four-factor central composite design (CCD) was utilized using Design Expert software (version 8.0.6; Stat-Ease, Minneapolis, MN, USA). The independent variables and their coded levels and scheme matrix of the CCD are represented in Tables 3 and 4, respectively. CCD was employed to determine the effect of temperature $\left(30^{\circ} \mathrm{C}-70^{\circ} \mathrm{C}\right.$, $\left.\mathrm{X}_{1}\right)$, addition rate $\left(0.9-2.1 \mathrm{~mL} / \mathrm{min}, \mathrm{X}_{2}\right)$, and water content $\left(30-70 \mathrm{wt} \%, \mathrm{X}_{3}\right)$, as well as the effect of mixing rate (480-800 rpm, $\mathrm{X}_{4}$ ) on two response variables: average droplet size $\left(\mathrm{Y}_{1}\right)$ and PDI $\left(\mathrm{Y}_{2}\right)$ of nanoemulsions. As such, based on the $\mathrm{CCD}$, a total of 30 experiments were run involving

Table 2 Phase-inversion composition for preliminary nanoemulsion screening

\begin{tabular}{ll}
\hline Emulsification-processing parameters & $\mathbf{W t} \%$ \\
\hline Emulsification temperature $\left({ }^{\circ} \mathrm{C}\right)$ & $20,30,40,50,60$ \\
Addition rate $(\mathrm{mL} / \mathrm{min})$ & $0.3,0.6,0.9,1.2,1.5,1.8$ \\
Mixing rate $(\mathrm{rpm})$ & $400,480,560,640,720$ \\
\hline Notes: Numbers in bold indicate processing parameters kept constant, while \\
the others were varied. A series of emulsions was prepared with similar overall \\
compositions (5 wt \% Tegosoft G20, 22.5 wt $\%$ Tween $80,22.5$ wt\% glycerol, \\
50 wt\% water).
\end{tabular}


Table 3 Independent and dependent variables established based on CCD

\begin{tabular}{llll}
\hline Independent variables & Level & & \\
\cline { 2 - 4 } & Low $(-\mathrm{I})$ & Middle $(\mathbf{0})$ & High $(+\mathrm{I})$ \\
\hline $\mathrm{X}_{1}$, temperature $\left({ }^{\circ} \mathrm{C}\right)$ & 40 & 50 & 60 \\
$\mathrm{X}_{2}$, addition rate $(\mathrm{mL} / \mathrm{min})$ & 1.2 & 1.5 & 1.8 \\
$\mathrm{X}_{3}$, water content $(\mathrm{wt} \%)$ & 40 & 50 & 60 \\
$\mathrm{X}_{4}$, mixing rate $(\mathrm{rpm})$ & 560 & 640 & 720 \\
\hline Dependent variables & & & Goal \\
\hline $\mathrm{Y}_{1}$, particle size & & & Minimize \\
$\mathrm{Y}_{2}$, PDI & & & Minimize \\
\hline
\end{tabular}

Abbreviations: CCD, central composite design; PDI, polydispersity index.

16 factorial points, eight axial points, and six replicates of center points. Experiments were performed in randomized order, in order to minimize the effects of unexplained variability in the actual responses due to extraneous factors. The choice of CCD as the experimental design is used to estimate factor effects, to evaluate interaction effect between factors, and to permit optimization in the full factor space. ${ }^{18}$

\section{Statistical analysis}

Response surface analysis was performed to obtain the desired formulation of the sphingolipid-loaded nanoemulsion carrier with respect to temperature $\left(\mathrm{X}_{1}\right)$, addition rate $\left(\mathrm{X}_{2}\right)$, water content $\left(\mathrm{X}_{3}\right)$, and mixing rate $\left(\mathrm{X}_{4}\right)$. The main objective was to determine the optimal composition and conditions of formulations for attaining minimum particle size $\left(\mathrm{Y}_{1}\right)$ and lowest PDI $\left(\mathrm{Y}_{2}\right)$. The responses were then analyzed jointly by conferring to them either the same importance or weight for simultaneous optimization of multiple responses. ${ }^{19}$

A second-order polynomial equation effectively expressed the responses to the selected independent variables. The generalized response surface model is shown by the following equation:

$$
\begin{aligned}
Y_{i}= & a_{0}+a_{1} X_{1}+a_{2} X_{2}+a_{3} X_{3}+a_{4} X_{4}+a_{12} X_{1} X_{2} \\
& +a_{13} X_{1} X_{3}+a_{14} X_{1} X_{4}+a_{23} X_{2} X_{3}+a_{24} X_{2} X_{4} \\
& +a_{34} X_{3} X_{4}+a_{11} X_{1}^{2}+a_{22} X_{2}^{2}+a_{33} X_{3}^{2}+a_{44} X_{4}^{2}
\end{aligned}
$$

\begin{tabular}{|c|c|c|c|c|c|c|c|}
\hline \multirow[t]{2}{*}{ Run } & \multirow[t]{2}{*}{ Type } & \multicolumn{3}{|c|}{ Independent variables } & \multicolumn{3}{|c|}{ Response variables } \\
\hline & & $\begin{array}{l}\text { Temperature } \\
\left(\mathbf{X}_{1}\right),{ }^{\circ} \mathrm{C}\end{array}$ & $\begin{array}{l}\text { Addition rate } \\
\left(X_{2}\right), \mathrm{mL} / \mathrm{min}\end{array}$ & $\begin{array}{l}\text { Water content } \\
\left(\mathbf{X}_{3}\right), \text { wt\% }\end{array}$ & $\begin{array}{l}\text { Mixing rate } \\
\left(X_{4}\right), \text { rpm }\end{array}$ & $\begin{array}{l}\text { Particle size } \\
\left(Y_{1}\right), \mathrm{nm}\end{array}$ & $\begin{array}{l}\text { PDI } \\
\left(Y_{2}\right)\end{array}$ \\
\hline 1 & Factorial & 60 & 1.8 & 60 & 560 & 33.02 & 0.37 \\
\hline 2 & Factorial & 40 & 1.8 & 60 & 560 & 23.89 & 0.304 \\
\hline 3 & Factorial & 60 & 1.8 & 60 & 720 & 22.25 & 0.218 \\
\hline 4 & Axial & 30 & 1.5 & 50 & 640 & 23.41 & 0.177 \\
\hline 5 & Factorial & 40 & 1.2 & 60 & 560 & 31.67 & 0.111 \\
\hline 6 & Center & 50 & 1.5 & 50 & 640 & 19.85 & 0.155 \\
\hline 7 & Axial & 50 & 0.9 & 50 & 640 & 25.99 & 0.113 \\
\hline 8 & Factorial & 40 & 1.8 & 40 & 720 & 15.8 & 0.108 \\
\hline 9 & Center & 50 & 1.5 & 50 & 640 & 17.34 & 0.135 \\
\hline 10 & Axial & 50 & 2.1 & 50 & 640 & 18.86 & 0.142 \\
\hline 11 & Axial & 50 & 1.5 & 30 & 640 & 11.12 & 0.157 \\
\hline 12 & Center & 50 & 1.5 & 50 & 640 & $|7.0|$ & 0.168 \\
\hline 13 & Axial & 50 & 1.5 & 50 & 480 & 24.92 & 0.218 \\
\hline 14 & Axial & 70 & 1.5 & 50 & 640 & 31.8 & 0.243 \\
\hline 15 & Factorial & 60 & 1.2 & 40 & 560 & 19.7 & 0.134 \\
\hline 16 & Axial & 50 & 1.5 & 50 & 800 & $12.0 \mid$ & 0.12 \\
\hline 17 & Axial & 50 & 1.5 & 70 & 640 & 26.38 & 0.247 \\
\hline 18 & Factorial & 40 & 1.2 & 40 & 720 & 18.24 & 0.236 \\
\hline 19 & Factorial & 60 & 1.2 & 40 & 720 & 17.84 & 0.22 \\
\hline 20 & Factorial & 60 & 1.2 & 60 & 720 & 22.04 & 0.168 \\
\hline 21 & Factorial & 40 & 1.2 & 40 & 560 & 12.47 & 0.118 \\
\hline 22 & Factorial & 60 & 1.2 & 60 & 560 & 40.12 & 0.198 \\
\hline 23 & Factorial & 40 & 1.2 & 60 & 720 & 15.98 & 0.067 \\
\hline 24 & Factorial & 60 & 1.8 & 40 & 720 & 19.58 & 0.146 \\
\hline 25 & Factorial & 60 & 1.8 & 40 & 560 & 14.88 & 0.157 \\
\hline 26 & Factorial & 40 & 1.8 & 40 & 560 & 11.52 & 0.143 \\
\hline 27 & Center & 50 & 1.5 & 50 & 640 & 17.09 & 0.193 \\
\hline 28 & Factorial & 40 & 1.8 & 60 & 720 & 16.84 & 0.119 \\
\hline 29 & Center & 50 & 1.5 & 50 & 640 & 17.46 & 0.166 \\
\hline 30 & Center & 50 & 1.5 & 50 & 640 & 17.03 & 0.19 \\
\hline
\end{tabular}

Table 4 CCD scheme: independent and response variables

Abbreviations: $\mathrm{CCD}$, central composite design; $\mathrm{PDI}$, polydispersity index. 
where $\mathrm{Y}_{\mathrm{i}}$ is the predicted response, $\mathrm{X}_{\mathrm{i}}$ the independent variables, $\mathrm{a}_{0}$ a constant, $\mathrm{a}_{\mathrm{i}}, \mathrm{a}_{\mathrm{ii}}$, and $\mathrm{a}_{\mathrm{ij}}$ the linear, quadratic, and interactive coefficients, respectively.

An appropriate polynomial model was chosen, based on the statistical significance of the model $(P<0.05)$ and the lack-of-fit value of the model provided by Design-Expert software not being significant. ${ }^{19}$ The goodness of fit of the model was evaluated by coefficient determination $\left(R^{2}\right)$ and analysis of variance (ANOVA). ${ }^{20}$ Significant differences between independent variables were determined by ANOVA. Response surfaces and 3D contour plots of the fitted polynomial-regression equations were generated to visualize the interaction effect of the independent variables on responses better. ${ }^{21}$

\section{Verification of models}

Experimental data obtained for average droplet size and PDI for ceramide IIIB nanoemulsions prepared under recommended conditions according to CCD are presented in Table 4. Verification of the final reduced models was performed by comparing the experimental values with the predicted value obtained from the response-regression equations. ${ }^{22}$

\section{Emulsion-droplet size and polydispersity- index measurement}

Mean droplet size and size distribution were measured by dynamic light scattering with a Malvern Zetasizer Nano ZS90 (Malvern Instruments, Malvern, UK) by diluting $1 \mathrm{~mL}$ of the nanoemulsion with $20 \mathrm{~mL}$ of water. Each nanoemulsion was diluted with distilled water to weak opalescence. ${ }^{23}$ Measurements were carried out at $25^{\circ} \mathrm{C}$ with a scattering angle of $90^{\circ}$. Size distribution was represented by PDI values. PDI values $<0.25$ indicated a narrow size distribution providing good stability of nanoemulsions. ${ }^{24}$

\section{Morphological analysis}

Morphological examination and globular size confirmation of the nanoemulsions were performed using transmission electron microscopy (TEM). In order to perform TEM observations, the nanoemulsion containing ceramide IIIB was first diluted in water (1:10), and a drop of the diluted emulsion was then directly deposited on the holey copper grid and treated with a drop of $2 \%(\mathrm{w}: \mathrm{v})$ phosphotungstic acid and left for 30 seconds at room temperature. Excess liquid was blotted with a piece of Whatman filter paper, and the sample was dried at room temperature. Photographs of the drops were obtained using TEM (H-7650; Hitachi, Tokyo, Japan) under high-voltage electricity of $80 \mathrm{kV}$.

\section{Results and discussion Physicochemical properties of nanoemulsion ingredients}

The choice of octyldodecanol as the internal phase of the nanoemulsion was based on the following consideration. With respect to the solubility capacity of sphingolipids, octyldodecanol is considered a very high-solubility excipient suitable for use as a vehicle for incorporating ceramide IIIB. Table 5 shows the results of the dissolution test for $1 \mathrm{wt} \%$ ceramide IIIB in different cosmetic oils. We chose octyldodecanol as the oil phase based on these advantages, which improved the pharmacokinetic activity of drugs and enhanced skin penetration.

\section{Screening emulsion in phase-diagram structure}

The most important criterion for the development of nanoemulsion systems is that all the excipients depend upon the requirement and fall under the category "generally regarded as safe". ${ }^{17}$ The screening of the component can be illustrated with the help of the pseudoternary phase diagram with a nanoemulsion-formation zone.

\section{Effect of ethanol, PG, and glycerol in Tegosoft G20 and TW80 systems}

For selection of cosurfactants, pseudoternary phase diagrams were plotted with different cosurfactants, ie, PG, glycerol, and ethanol (Figure S1). A distinct conversion from a slightly sticky liquid to a clear one and finally to a turbid liquid was observed. The sizes of the nanoemulsion region in the phase diagrams were compared at a fixed $S_{\text {mix }}$ ratio $(1: 1)$ for the same surfactant and oil phases. Incorporation of PG significantly increased the water incorporation when the chain length was increased from ethanol (Figure 1A) to PG (Figure 1B). The effect of PG on the area of the nanoemulsion region was a little superior to slightly better than the effect of glycerol (Figure 1C).

The conversion from optically transparent liquid to slightly turbid liquid was affected by the effect of cosurfactants on

Table 5 Dissolution-test results for I wt\% ceramide IIIB in different cosmetic oils

\begin{tabular}{lll}
\hline Oil phase & $\begin{array}{l}\text { Recrystallization } \\
\text { temperature }\left({ }^{\circ} \mathbf{C}\right)\end{array}$ & Crystallinity \\
\hline Tegosoft G20 & 45 & Medium \\
Varonic APM & 65 & Medium-high \\
Tegosoft TN & 75 & High \\
Tegosoft DC & 80 & High \\
Tegosoft CT & 85 & High \\
Mineral oil & 115 & High \\
\hline
\end{tabular}

Note: Information kindly provided by Evonik, Essen, Germany. 
particle size and the influence of cosurfactants on the optical clarity of nanoemulsions. At the same time, the stability of the system has a direct relationship with optical clarity. ${ }^{25}$ The influence of PG, ethanol, and glycerol on the properties of the system would be expected to impact the tendency for small droplets to be formed by the spontaneous emulsification method, as described elsewhere. ${ }^{26,27}$ The difference among nanoemulsion sizes in the different systems investigated was mainly due to the nature of the cosurfactant.

PG and ethanol have similar backbone structures, consisting of $\mathrm{H}_{3} \mathrm{C}-(\mathrm{CHOH})-$; however, $\mathrm{PG}$ has a $-\mathrm{CH}_{2} \mathrm{OH}$ group attached to the backbone, while ethanol only has $\mathrm{a}-\mathrm{H}$ attached. ${ }^{27} \mathrm{PG}$ and glycerol (having one more hydroxyl group than PG), which form hydrogen bonds like water, have relatively high dielectric constants and are immiscible with hydrocarbon solvents. ${ }^{28}$ This difference in their molecular properties will alter their interactions with Tegosoft G20, water, and TW80 molecules.

Cosurfactants can alter the properties of surfactants in emulsions, probably due to different physicochemical or molecular phenomena. ${ }^{27}$ First, the presence of cosurfactants may modulate the solubility of surfactant monomers in aqueous solutions by altering the magnitude of the hydrophobic effect. Second, cosurfactant molecules may alter the packing and optimum curvature of the surfactant monolayers through their ability to compete with water molecules, thereby partially dehydrating the hydrophilic head groups of surfactants. ${ }^{26,27}$ Third, some cosurfactants change their optimum curvature and decrease the elasticity of surfactant film by penetrating the hydrophilic head-group region of surfactant monolayers. ${ }^{29,30}$ Glycerol affects the surfactant aggregation and its structure due to dehydration. ${ }^{29}$ The other part of the cosurfactant molecules resides in the water and decreases the polarity of water by interfering with its hydrogen-bonding network. ${ }^{31,32}$ The mechanism of droplet formation has been partly attributed to the solubility and optimum curvature of the surfactants. ${ }^{33}$ According to Shiao et al, ${ }^{34}$ the mutual miscibility between the hydrophobic part of the surfactant and the oil will influence the degree of oil penetration into the amphiphilic film (the boundary between the organic phase and the aqueous phase) and will also affect spontaneous curvature. ${ }^{31}$

The dependence of droplet size on the cosurfactants may be attributed to the differences between their abilities to alter the various aforementioned mechanisms, eg, surfactant solubility, density, and viscosity of aqueous solutions, and optimum curvature, interfacial rheology, thickness, interfacial tension, and flexibility. ${ }^{26,27}$ Nanoemulsions containing
$20 \%$ ethanol appear less pellucid than those containing $30 \% \mathrm{PG}$, despite the former system comprising slightly smaller droplets. ${ }^{27}$ Saberi et al showed that nanoemulsions with smaller droplets can be produced using higher glycerol concentrations. ${ }^{26}$ It has been reported that the refractive index has a significant impact on the optical properties of emulsions, ${ }^{35}$ and smaller droplets scatter light less strongly than larger ones. ${ }^{36}$ An emulsion with a refractive index of 1.37 correspond to aqueous solutions with PG concentration of $30 \%$ and ethanol concentration of $20 \%$, the corresponding refractive index of which is $1.34 .{ }^{27}$ The refractive index of aqueous glycerol solutions has been reported to increase from 1.33 to 1.40 upon increasing glycerol concentration from $0 \%$ to $50 \%{ }^{26}$ Although the oil phases in these experiments were different, there is a reference value in this respect compared to the trend in refractive index. Therefore, it can be speculated that light scattering from a nanoemulsion containing ethanol should be greater than that from a nanoemulsion containing PG and that the light scattering from the nanoemulsion containing PG is greater than that from the one containing glycerol, resulting in differences in the size of the phasediagram area.

The skin-moisturizing effect depends on the amount of absorbed humectant and the physicochemical properties in the stratum corneum. ${ }^{37}$ The important pharmacological properties of glycerol visually confirmed by preliminary clarity studies ${ }^{37-39}$ are as follows: it is hygroscopic, has keratolytic effect by desmosome degradation, has smoothing effects, and protects emulsion systems against irritations. Additionally, treatments with glycerol in water reversed skin dryness and erythema ${ }^{40}$ Also, recent findings have proved that glycerol creates a stimulus for barrier repair and improves stratum corneum hydration. ${ }^{41}$ That investigation showed that the glycerol effect persists for an extraordinarily long period. Therefore, glycerol was considered a more desirable cosurfactant compared to PG.

The interfacial equilibrium was due to the intermolecular forces among Tegosoft G20, TW80, and the three types of cosurfactants. The TW80 is a nonionic surfactant favoring van der Waals forces and hydrogen bonds. ${ }^{42}$ It should be emphasized that these conjectures need to be proved by identifying the precise mechanisms involved, as a part of future endeavors.

\section{Effect of surfactant:cosurfactant mass ratio on nanoemulsion formation}

The relationship between the phase behavior of nanoemulsions and the mass ratio of surfactant:cosurfactant 
can be captured with the aid of a pseudoternary phase diagram. ${ }^{43}$ The system underwent a transition from transparent to translucent to opaque, via rearrangements of the ingredients within the nanoemulsion phase and the light-scattering behavior of the system. Nanoemulsions containing higher or lower levels of glycerol were either optically transparent or opaque, due to varied light scattering by droplets of different sizes. ${ }^{26}$ Nanoemulsion area was used as the assessment criteria for the evaluation of surfactant:cosurfactant mass ratio. The larger the area of the nanoemulsion region, the greater the nanoemulsification efficiency of the system.

The phase diagram of the three-component system of Tegosoft G20-Tween 80-water is presented in Figure S2A. A limited microemulsion-formation zone was obtained. Alteration in the phase diagram in the presence of glycerol is shown in Figure S2B-F. Glycerol was added at a 1:1 weight ratio to Tween 80 . The change in the size of the phase diagram was dramatic. Possible explanations for the increase in phase-diagram area are increased incorporation of glycerol into the surfactant film and decreased polarity of water, sufficiently reducing interfacial tension and favoring formation of $\mathrm{O} / \mathrm{W}$ nanoemulsion. ${ }^{44}$ On further increasing of the TW80 concentration, ie, at $\mathrm{S}_{\text {mix }}$ ratio $2: 1$ (Figure $\mathrm{S} 2 \mathrm{E}$ ), the region increased in size compared to $S_{\text {mix }}$ ratio 1:0 and $\mathrm{S}_{\text {mix }}$ ratio 1:1. Although TW80 concentration was further increased for the $S_{\text {mix }}$ ratio of 3:1 (Figure S2F), a decrease in area was noticed when compared with $\mathrm{S}_{\text {mix }}$ ratio $2: 1$. The region of the phase diagram shrank, implying that the lowest interfacial tension and optimum curvature had been achieved. Therefore, performing the test with an $\mathrm{S}_{\text {mix }}$ ratio of $4: 1$ was redundant. When glycerol concentration with respect to TW80 was increased to obtain $\mathrm{S}_{\text {mix }}$ ratio 1:2 (Figure $\mathrm{S} 2 \mathrm{C}$ ), it was observed that the area decreased compared to $\mathrm{S}_{\text {mix }}$ ratio $1: 1$. When glycerol concentration was further raised to make an $\mathrm{S}_{\text {mix }}$ ratio of 1:3 (Figure $\mathrm{S} 2 \mathrm{D}$ ), a further decrease in the area was attained.

At relatively low glycerol concentrations, mean particle diameter increased with increasing surfactant concentration. An optimum concentration of glycerol provides an ideal balance between the dehydration rate of the polar heads of Tween 80 and the viscosity of the aqueous phase, which provides an adequate rate of insertion of the surfactant molecules into the interface. ${ }^{45}$ The TW80:glycerol weight ratio was the key factor influencing the appearance of nanoemulsions and affecting the area of nanoemulsion regions. High glycerol concentrations may dehydrate the polar heads of polysorbate molecules too quickly and intensely, ${ }^{29}$ leading to high reduction in the hydrophilic-lipophilic balance of the surfactant and preventing their proper accommodation in the oil-water interface. ${ }^{46}$ Glycerol contains three hydroxyl groups; therefore, an increase in glycerol concentration accompanied by a reduction in TW80 concentration made spontaneous breakup of the oil-water interface more difficult without a decrease in interfacial tension. Areas of $\mathrm{O} / \mathrm{W}$ nanoemulsion zones are known to be dependent on surfactant contention. ${ }^{47}$ In consideration of the fact that increased surfactant amounts will irritate the skin and that glycerol is beneficial to skin, TW80:glycerol mass ratio of 1:1 (Figure 2), which produced a broader nanoemulsion region in the phase diagram, was selected for further research.

\section{Preliminary screening experiment}

The influence of composition parameters, including the oil:surfactant weight ratio and the water fraction, was investigated systematically. The study was restricted to a Tegosoft G20:Tween 80/glycerol weight-ratio range of 1:9-3:7 and a water-weight range of 30-70. Moreover, the formation of nanoemulsions also depends on preparation conditions. ${ }^{33,45}$ The aim of the preliminary screening experiment was to screen the appropriate factors for experimental design optimization. The factors considered in preliminary screening experimentation were emulsification temperature, addition rate, and mixing rate.

\section{Effect of emulsification temperature}

In this series of experiments, we examined the influence of emulsification temperature on particle size and PDI values of the nanoemulsions produced using PIC. This information is important for the rational design of nanoemulsion-based delivery systems. The results are shown in Figure 3, which shows that the smallest PDI value was produced at $50^{\circ} \mathrm{C}$. It was found that reducing the emulsification temperature from $50^{\circ} \mathrm{C}$ to $20^{\circ} \mathrm{C}$ had little effect on mean droplet size. Increasing emulsification-energy input by raising the temperature from $50^{\circ} \mathrm{C}$ to $60^{\circ} \mathrm{C}$ led to a significant increase in droplet size from 14.74 to $30.19 \mathrm{~nm}$. This result corresponds with a reported study, ${ }^{48}$ which indicated that bigger droplet sizes were produced when

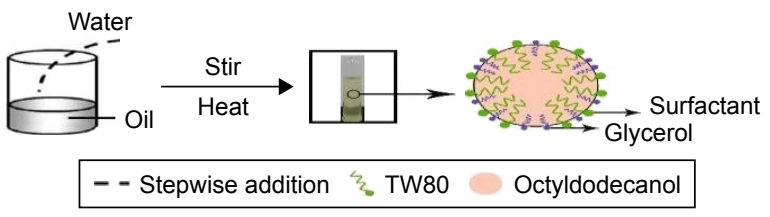

Figure 2 Proposed mechanism for phase-inversion composition for production of ceramide IIIB nanoemulsion: mass ratio of TW80 to glycerol is I:I. 


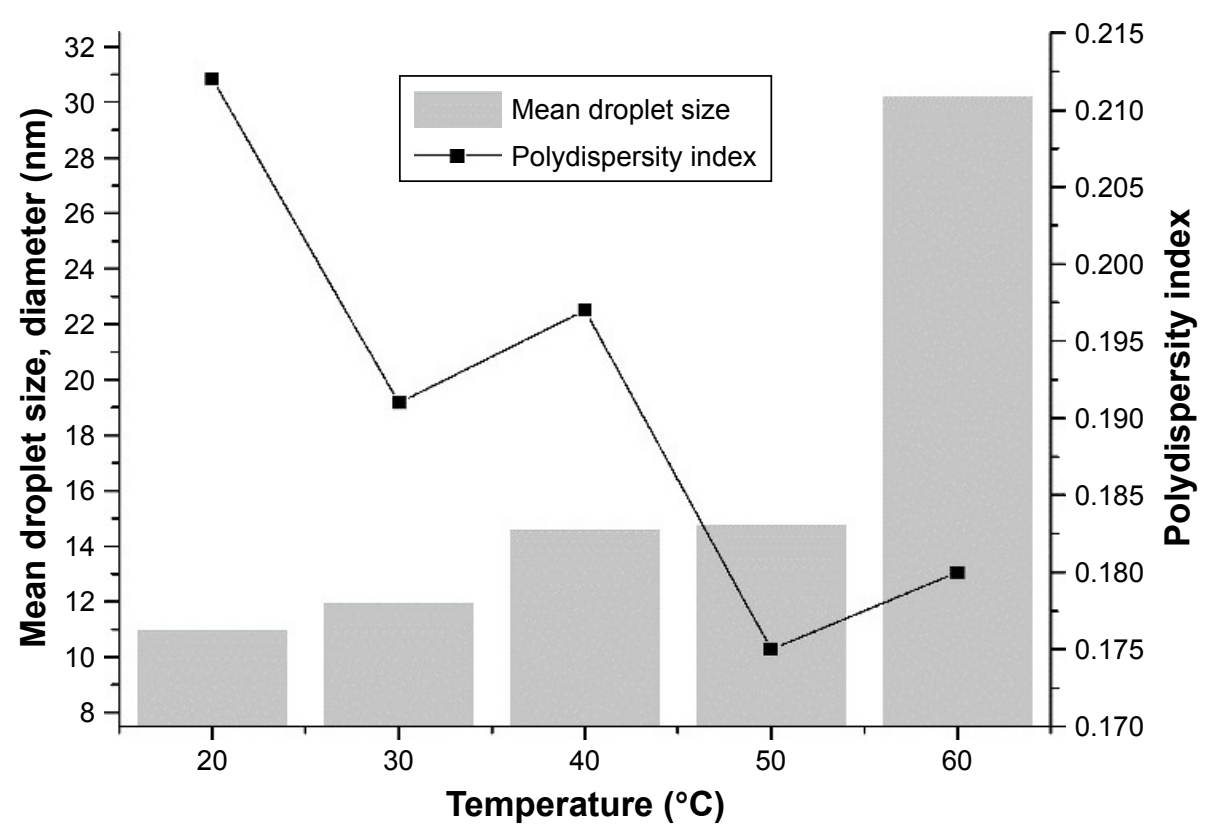

Figure 3 Effect of temperature on mean droplet size and polydispersity index.

the temperature was increased to $60^{\circ} \mathrm{C}$. The observed changes in particle size and PDI values with increasing temperature may have occurred for a number of reasons.

The original oil drop rapidly divided into many small oil drops at moderately high temperatures, inducing fast dispersion and high degree of dispersion of the emulsion. ${ }^{49}$ The nature of the oil phase also alters phase-inversion temperature. Glycerol can modulate the properties of TW80 and influence the size of droplets and size distribution, ${ }^{26}$ probably because glycerol can dehydrate the polar head groups of the nonionic surfactant molecules, thereby altering their optimum curvature and decreasing their cloud point. ${ }^{50,51}$ The same trend was also observed for the system based on Tween $80 .{ }^{31}$ Previous research has confirmed that the effect of Tween 80 is highly dependent on temperature. ${ }^{24}$ Increased temperature enhanced the solubility of TW80, making the surfactant more soluble in the oil phase and affecting the spontaneous curvature of the surfactant film. The head group of Tween 80 becomes progressively dehydrated with increasing temperature. ${ }^{52}$ In addition, head-group dehydration means that the packing parameters of surfactant molecules tend toward unity, producing an ultralow interfacial tension, which in turn promotes the formation of $\mathrm{O} / \mathrm{W}$ nanoemulsions. ${ }^{52}$ However, high temperatures decrease the solubility of the hydrophilic surfactant by dehydration of the polar head group of the nonionic surfactant molecules, probably leading to leakage of TW80 from the oil-water interface, ${ }^{24}$ thereby allowing aggregation of droplets. These factors may have facilitated the formation of smaller droplets and closer size distribution at $50^{\circ} \mathrm{C}$, leading to a lower extent of Ostwald ripening. In our study, $50^{\circ} \mathrm{C}$ was selected as the optimum temperature because it gave relatively uniform emulsion droplets.

\section{Effect of addition rate}

The purpose of these experiments was to examine the influence of addition rate on nanoemulsion characteristics by PIC. The overall composition of the different systems was kept constant, but addition rate was varied. There were appreciable differences in droplet size and PDI values that could be produced by the low-energy method, depending on addition rate (Figure 4). We found that the smallest droplets were formed at an addition rate of $1.5 \mathrm{~mL} / \mathrm{min}$ : diameter $11.93 \mathrm{~nm}$ and PDI value 0.191 . Nanoemulsions with narrow size distributions were also produced at addition rates of $0.6 \mathrm{~mL} / \min$ (diameter $27.92 \mathrm{~nm}$ and PDI value 0.189 ) and $0.9 \mathrm{~mL} / \mathrm{min}$ (diameter $23.65 \mathrm{~nm}$ and PDI value 0.187 ), but the droplets formed were appreciably larger than those produced at an addition rate of $1.5 \mathrm{~mL} / \mathrm{min}$. The addition rate is an important factor and should be adjusted to ensure it is slow enough for the $\mathrm{O} / \mathrm{W}$ phase to be formed. Low addition rates allow the system time to equilibrate. If addition time is very long, these relatively unstable samples start to destabilize, leading to increased droplet size..$^{53}$

\section{Effect of mixing rate}

The effect of mixing rate on the formation of small droplets and PDI values was investigated by preparing a series of 


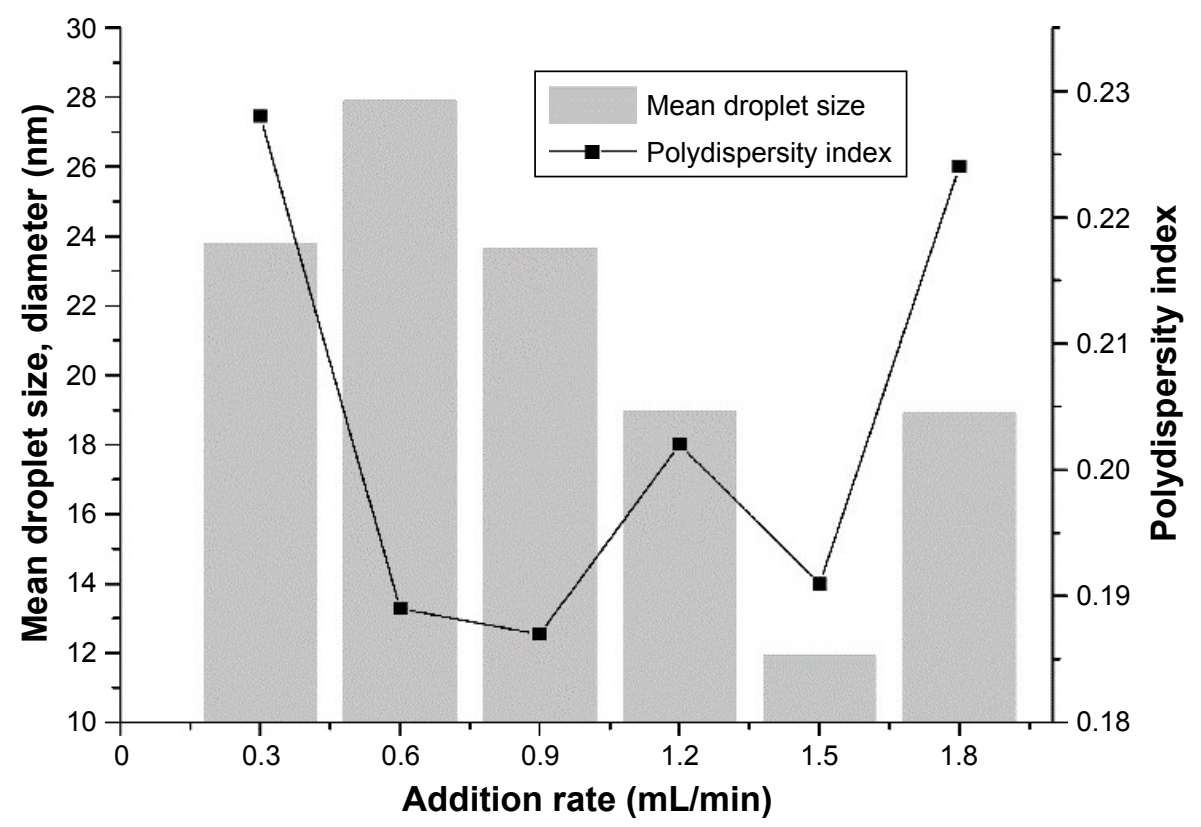

Figure 4 Effect of addition rate on mean droplet size and polydispersity index.

emulsions of fixed composition (Figure 5). The smallest mean droplet size was observed at a stirring speed of $640 \mathrm{rpm}$ for the emulsions prepared. Droplet size was effectively reduced from $83.96 \mathrm{~nm}$ to $11.93 \mathrm{~nm}$ upon an increase in mixing rate from $320 \mathrm{rpm}$ to $640 \mathrm{rpm}$, which corresponded to previous results. ${ }^{54}$ The width of the particle-size distribution was not strongly influenced by mixing rate, as described by Saberi et al. ${ }^{55}$

Similar results were observed for emulsion-droplet size and mixing rate for emulsification of nanoemulsions. ${ }^{53,56}$
Previous studies ${ }^{55,57}$ suggested that gentle mixing was needed to form very fine droplets, highlighting the importance of controlling this parameter. Mixing had to be more vigorous to obtain phase transitions. Droplet size was reduced upon an increase in mixing rate, because the applied mechanical energy broke up and ensured an even distribution of the surfactant-oil phase in the aqueous phase..$^{58}$ If the mixing rate was too high, it promotes destabilization mechanisms like coalescence and sedimentation, resulting in larger final droplets. ${ }^{53}$

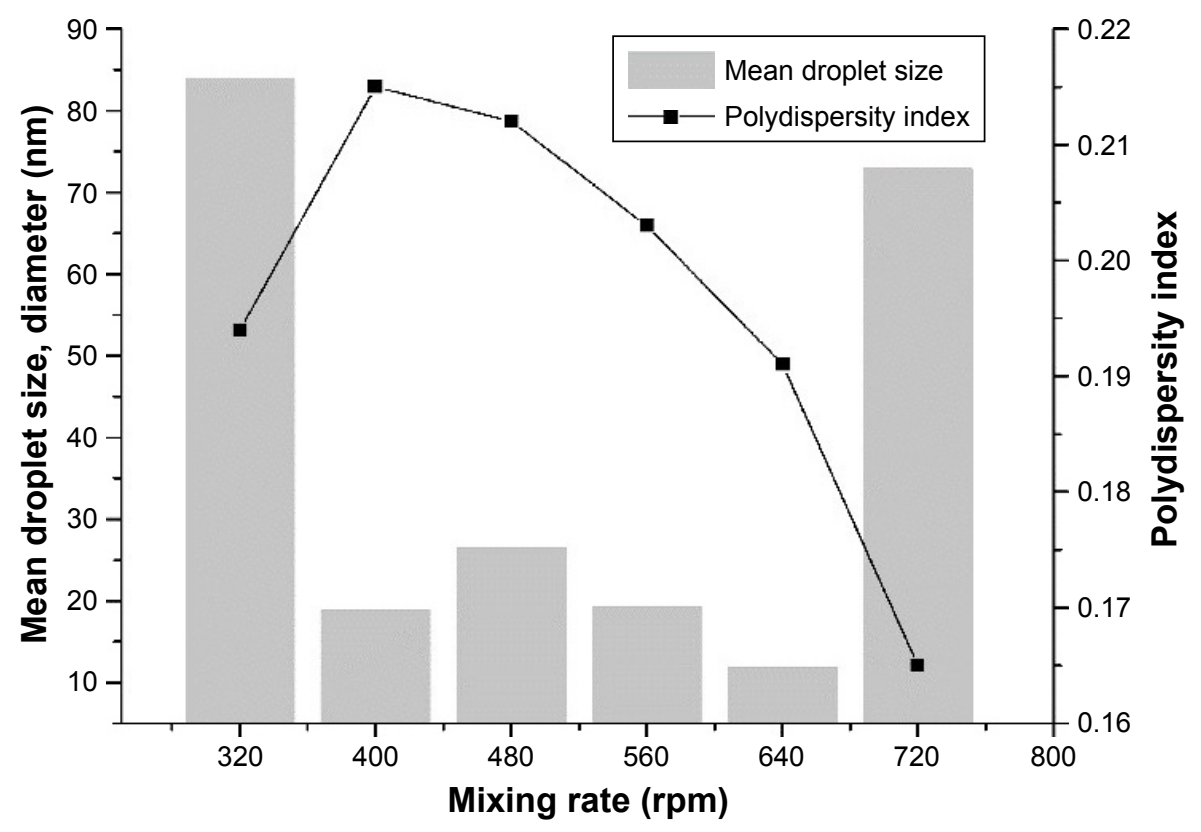

Figure $\mathbf{5}$ Effect of mixing rate on mean droplet size and polydispersity index. 


\section{Effect of Tegosoft G20:Tween 80/glycerol weight ratio}

In this series of experiments, we investigated the influence of oil:(surfactant:cosurfactant) ratio (OSR) on droplet size and particle-size distribution of nanoemulsions produced by PIC (Figure 6). Both mean particle diameter and PDI values reduced upon a decrease in OSR. This variation agrees with earlier reports on nanoemulsions prepared by PIC..$^{33,45}$

There was a rapid decrease in interface pressure with decreasing molecular volume of the surfactant and cosurfactant. The presence of glycerol strongly influenced the formation of nanoemulsions by PIC. ${ }^{46}$ Upon addition of water, the normal tendency of Tween 80 molecules was to migrate to a water-rich environment and to accommodate themselves in an oil-water interface. The presence of glycerol lowered the solubility of Tween 80 in the aqueous phase ${ }^{59}$ Control of the migration rate of Tween 80 molecules from the oil to aqueous phase was also controlled by the influence of glycerol on their solubility, as well as by the increase in viscosity of the aqueous phase with greater amounts of glycerol. ${ }^{46}$

Formation of emulsions was influenced by an equivalence between the two main mechanisms: droplet disruption and droplet coalescence. The surfactants play major roles in the deformation and breakup of droplets. Surfactants allow the existence of interfacial tension gradients, which is crucial for the formation of stable droplets. ${ }^{13}$ The rate of droplet coalescence was determined by the ability of the emulsifier to form an absorbed monolayer rapidly onto the newly formed interface, ${ }^{22}$ mainly governed by emulsifier concentration.
In fact, the emulsifier played a vital role in the formation of emulsions by lowering interfacial tension. ${ }^{22}$ Surfactant concentration controls the total surface area of the droplets, rate of droplet dispersion, and coalescence. ${ }^{58}$ The concentration of glycerol increases, affecting the properties of TW80 and forcing the glycerol to penetrate the interfacial region, accounting for the observed decrease in droplet size and particle-size distribution.

\section{Effect of water content}

The effects of water content on mean droplet size and size distribution of microemulsions are shown in Figure 7. There were distinct differences in the amount of water required to achieve the smallest droplets. At a constant OSR, decreasing water concentration from $70 \%$ to $30 \%$ had a tendency to produce smaller droplets and narrower size distribution. The smallest droplets (diameter $\sim 8.861 \mathrm{~nm}$ ) and minimum size distribution (PDI 0.088) were formed at $30 \%$ water concentration. The mean particle diameter decreased slightly from $40 \%$ to $30 \%$ water, remained relatively low from $40 \%$ to $50 \%$ water, increased slightly from $50 \%$ to $60 \%$ water, and finally increased steeply from $60 \%$ to $70 \%$ water. The width of PDI values increased with increasing water concentration (from $30 \%$ to $40 \%$ water), but the trend was similar to that obtained for size distribution between $40 \%$ and $70 \%$ water. Our results are consistent with research showing that particle size increases with increasing water content. ${ }^{60}$ Increasing water content eliminates rigid film, leading to coalescence of droplets and increased particle size. ${ }^{58}$

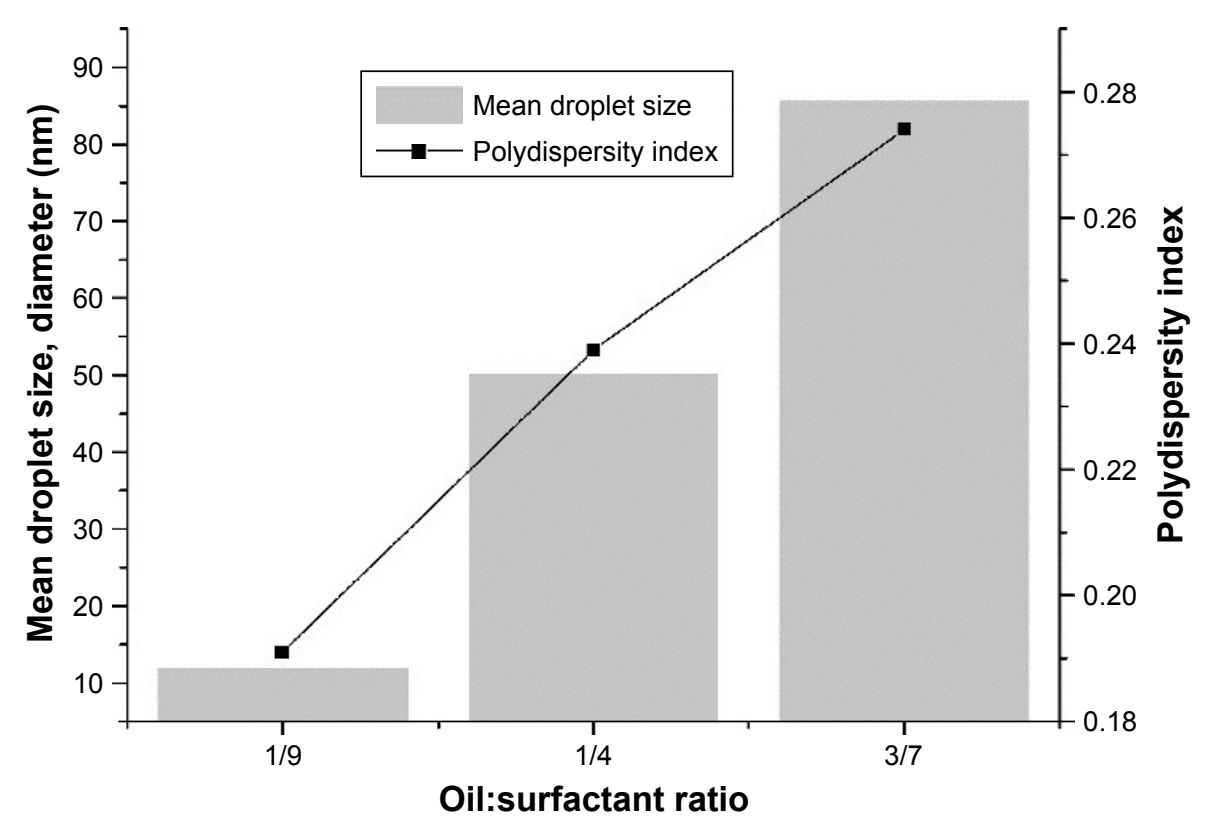

Figure 6 Effect of oil:surfactant ratio on mean droplet size and polydispersity index. 


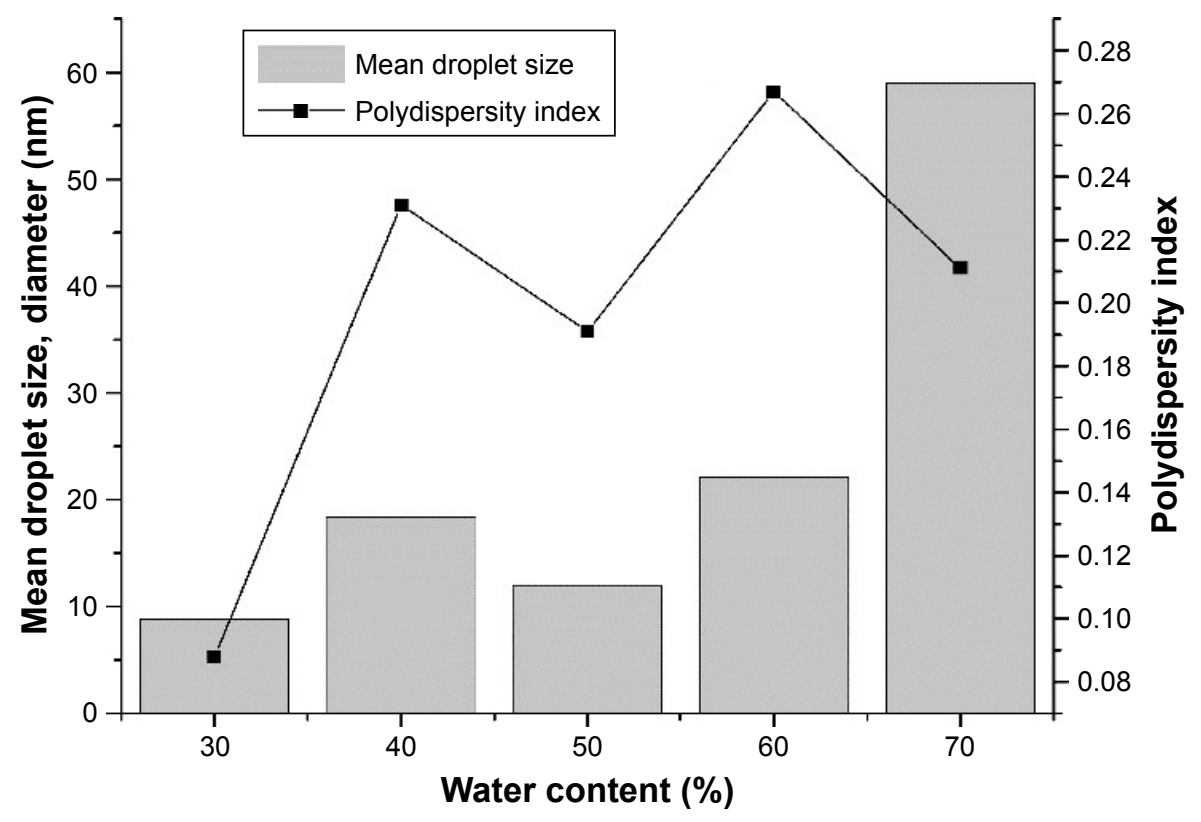

Figure 7 Effect of water content on mean droplet size and polydispersity index.

\section{Fitting response surface models}

Table 4 shows the experimental data for each response variable under different independent variables, according to the CCD matrix. Response surface models allow for the prediction of variations in particle size and PDI values in terms of nanoemulsion composition. The estimated regression coefficients, $R^{2}$, adjusted $R^{2}$, regression ( $P$-value and $F$-value), and standard deviation related to the effect of the three independent variables are presented in Table 6 . The ANOVA in Table 6 indicates that quadratic polynomial models were adequate for the prediction. The models showed no lack of fit because $P$-values for the particle size and PDI ( 0.1592 and 0.7885 , respectively) were $>0.05$. Insignificant lack of fit, together with the high $R^{2}$ and $R_{\mathrm{a}}^{2}$ values, indicated that the quadratic equation was capable of representing the system under the given experimental domain.

The response surface analysis indicated that the secondorder polynomial response model for particle size had higher coefficient value $\left(R^{2}=0.9731\right)$ than the response surface model for PDI $\left(R^{2}=0.9901\right)$. Observations showed that more than $90 \%$ of response variations of independent variables (particle size and PDI) were able to be adequately explained by the RSM model. It should be mentioned that

Table 6 ANOVA for the model

\begin{tabular}{llllll}
\hline Response variables & $\boldsymbol{F}$-value & $\boldsymbol{P}$-value & $\boldsymbol{R}^{2}$ & Adjusted $\boldsymbol{R}^{2}$ & $\mathbf{S D}$ \\
\hline Particle size $\left(\mathrm{Y}_{1}\right)(\mathrm{nm})$ & 38.8 & $<0.000 \mathrm{I}$ & $0.973 \mathrm{I}$ & 0.948 & $\mathrm{I}$ \\
\hline & 23.57 & $<0.000 \mathrm{I}$ & 0.9562 & 0.9152 & 0.018 \\
PDI $\left(\mathrm{Y}_{2}\right)$ & &
\end{tabular}

Abbreviations: ANOVA, analysis of variance; $\mathrm{PDI}$, polydispersity index. nonsignificant $(P<0.05)$ linear terms were included in the final reduced model if quadratic or interaction terms containing these variables were found to be significant $(P<0.05){ }^{61}$ The significance of the model and each coefficient was determined using $F$-test values and corresponding $P$-values (Table 7). Larger $F$-values and smaller $P$-values showed more

Table 7 Regression coefficients in final reduced second-order polynomial models

\begin{tabular}{|c|c|c|c|c|}
\hline & \multicolumn{2}{|c|}{ Particle size } & \multicolumn{2}{|l|}{ PDI } \\
\hline & $F$-value & $P$-value & $F$-value & $P$-value \\
\hline \multicolumn{5}{|c|}{ Linear effects } \\
\hline$X_{1}$ & 60.79 & $<0.000 \mathrm{I}^{\mathrm{a}}$ & 35.45 & $<0.000 I^{a}$ \\
\hline$x_{2}$ & 20.28 & $0.0004^{b}$ & 16.92 & $0.0009^{b}$ \\
\hline$x_{3}^{2}$ & 192.07 & $<0.000 \mathrm{I}^{\mathrm{a}}$ & 27.5 & $<0.000 I^{a}$ \\
\hline$X_{4}$ & 70.76 & $<0.000 \mathrm{I}^{\mathrm{a}}$ & 24.78 & $0.0002^{\mathrm{a}}$ \\
\hline \multicolumn{5}{|c|}{ Interaction effect } \\
\hline$X_{1} X_{2}$ & 0.003 & 0.9574 & 0.16 & $0.6993^{d}$ \\
\hline$x_{1} x_{3}$ & 5.8 & $0.0294^{c}$ & 16.71 & $0.0010^{\mathrm{b}}$ \\
\hline$X_{1} X_{4}$ & 4.52 & $0.0504^{d}$ & 0.28 & $0.604 I^{d}$ \\
\hline$x_{2} x_{3}$ & 1.37 & $0.2595^{d}$ & 71.11 & $<0.000 I^{a}$ \\
\hline $\mathrm{X}_{2} \mathrm{X}_{4}$ & 11.27 & $0.0043^{b}$ & 48.53 & $<0.000 I^{\mathrm{a}}$ \\
\hline $\mathrm{X}_{3} \mathrm{X}_{4}$ & 106.01 & $<0.000 \mathrm{I}^{\mathrm{a}}$ & 59.7 & $<0.000 I^{\mathrm{a}}$ \\
\hline \multicolumn{5}{|c|}{ Quadratic effect } \\
\hline $\mathrm{X}_{1}{ }^{2}$ & 62.16 & $<0.000 \mathrm{I}^{\mathrm{a}}$ & 8.69 & $0.01^{\mathrm{c}}$ \\
\hline$X_{2}^{2}$ & 12.62 & $0.0029^{a}$ & 8.52 & $0.0106^{c}$ \\
\hline$x_{3}^{2}$ & 0.23 & $0.639^{d}$ & 5.66 & $0.03 I^{c}$ \\
\hline $\mathrm{X}_{4}^{2}$ & 0.058 & $0.8133^{d}$ & 0.001 & $0.9744^{d}$ \\
\hline Lack of fit & 2.53 & $0.1592^{d}$ & 0.57 & $0.7885^{d}$ \\
\hline
\end{tabular}

Notes: ${ }^{p} P<0.000$ I; ${ }^{b} P<0.01 ; c P<0.05 ; d P>0.05 . X_{1}, X_{2}, X_{3}$, and $X_{4}$ are the linear, quadratic, and interaction terms of the quadratic polynomial equation, respectively; $\mathrm{X}_{1}$, temperature; $\mathrm{X}_{2}$, addition rate; $\mathrm{X}_{3}$, water content; $\mathrm{X}_{4}$, mixing rate. Abbreviation: PDI, polydispersity index. 
pronounced effects on the respective response variables. ${ }^{20,62,63}$ In this study, taking $F$-values ( 38.80 and 23.37 for particle size and PDI, respectively) into consideration, two models were found to be significant (Table 7).

Upon closer observation, the particle-size model showed that all linear term coefficients $\left(\mathrm{X}_{1}, \mathrm{X}_{2}, \mathrm{X}_{3}, \mathrm{X}_{4}\right)$, quadraticterm coefficients $\left(\mathrm{X}_{1}^{2}, \mathrm{X}_{2}^{2}\right)$, and interaction parameters $\left(\mathrm{X}_{1} \mathrm{X}_{3}\right.$, $\left.\mathrm{X}_{2} \mathrm{X}_{4}, \mathrm{X}_{3} \mathrm{X}_{4}\right)$ were significant $(P<0.05)$. Water content was the most significant single parameter, and influenced the size of the microemulsion, followed by mixing rate and temperature. The interaction of water amount and mixing rate $\left(\mathrm{X}_{3} \mathrm{X}_{4}\right)$ had a more significant effect than other interactions on the droplet size of the nanoemulsions.

For PDI response, the results showed that the linear term and quadratic term coefficient effects of temperature, addition rate, and water content were significant, as was evident from their respective $F$ - and $P$-values (Table 7). Based on the $F$-value obtained from the ANOVA (Table 6), interaction parameters $\left(\mathrm{X}_{2} \mathrm{X}_{3}, \mathrm{X}_{2} \mathrm{X}_{4}\right.$, and $\left.\mathrm{X}_{3} \mathrm{X}_{4}\right)$ showed high levels of significance compared to other terms. However, no significant difference $(P>0.05)$ was observed on the interaction parameters $\left(\mathrm{X}_{1} \mathrm{X}_{4}\right)$ or quadratic term coefficient of mixing rate $\left(\mathrm{X}_{4}^{2}\right)$. Apparently, the proportion of water content was of overriding importance in evaluating the response variations of droplet size and PDI in the studied range. For emulsification by lowenergy methods, composition variables have much higher influence than preparation variables ${ }^{64}$ Our results agreed with other studies, ${ }^{58,60}$ which showed that increased water fraction resulted in an increase in particle sizes.

\section{Response surface analysis}

3D graphs of the ANOVA were plotted to understand the effect of the independent variables on the response variables. Graphs of the response surface for particle size and size distribution were used to interpret significant interactions $(P<0.05)$ of the models.

\section{Particle size}

Generally, production of nanoemulsions with smaller droplet size is highly desirable in pharmaceutical and cosmetic industries because it provides extremely low surface tension for the whole system and the interfacial tension of $\mathrm{O} / \mathrm{W}$ droplets. ${ }^{22}$ Particle size is a crucial characteristic of nanoemulsions, influencing bioactive release rate and absorption. ${ }^{65}$

Figure 8 reveals the importance of effective parameters on the particle size of nanoemulsions. Variables with the largest effect on droplet size of nanoemulsions were the linear term of water content and the interaction terms of

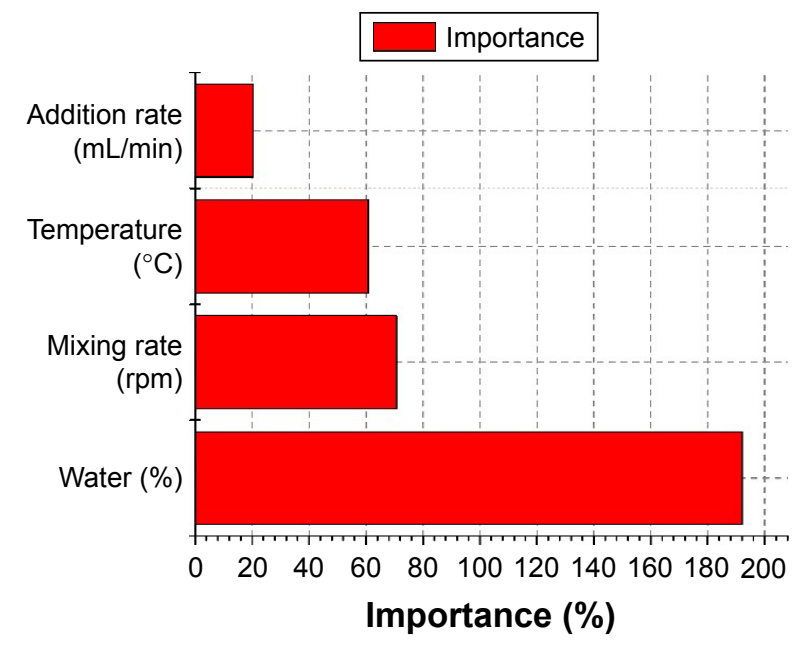

Figure 8 Importance of effective parameters on particle size of nanoemulsion.

water content and mixing rate, followed by the linear terms of mixing rate, temperature, and addition rate. Water content was one of the important factors affecting droplet size. The response surface graph (Figure 9A and C) indicates that droplet size significantly decreased with decreasing water content. The trend was consistent with those observed in earlier studies that droplet size was degraded at elevated emulsifier content. This could be due to the incomplete coverage of the fixed amount of emulsifier molecules on the newly formed droplets, leading to an increase in the particle size of an emulsion. ${ }^{21,66,67}$ Moreover, an increase in mixing rate $(P<0.05)$ slightly decreased droplet size (Figure 9B). These results were in good agreement with reports that the influence of mixing rate is more pronounced at high addition rates and that low addition rates and high mixing rates favor the formation of emulsions with small droplet size. ${ }^{53}$ The mechanism may be partly attributed to the rapid diffusion of surfactant molecules from oil to water.

With increasing temperature, droplet size first decreased and then increased (Figure 9A). Temperature played a significant role in affecting the emulsifying properties of nonionic TW80. The thermal deterioration of the emulsifier caused aggregation of neighboring droplets and increased mean droplet size. ${ }^{68}$ The result was as expected and coincided with the results obtained by $\mathrm{Yu}$ et $\mathrm{al},{ }^{45}$ who found that with increased preparation temperature, interfacial tension decreases due to relatively low interfacial tension and low viscous resistance of the oil phase.

\section{Polydispersity index}

As indicated in Table 7, interaction effects between addition rate and water content, between addition rate and mixing rate, and between water content and mixing rate exhibited 
A

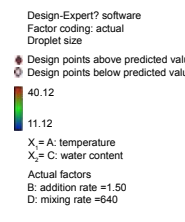

C

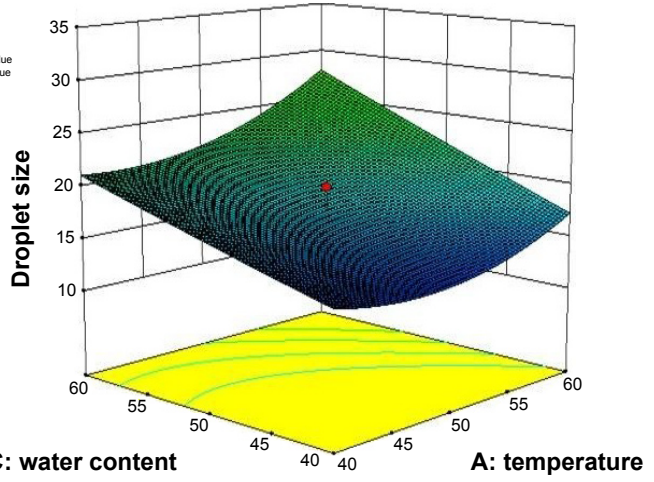

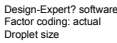

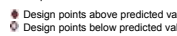

$\prod_{1.12}^{10,12}$

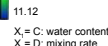

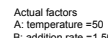

\section{E}

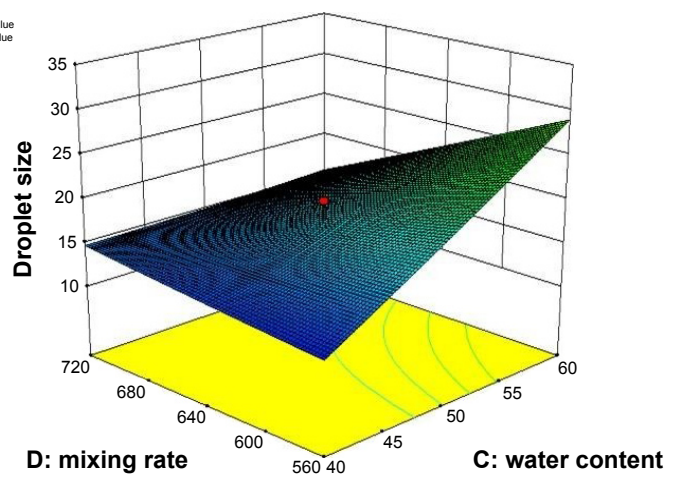

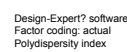

\& Design points above predicted value
Design points below predicted value

$\int_{0.067}^{0.37}$

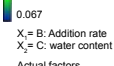

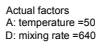

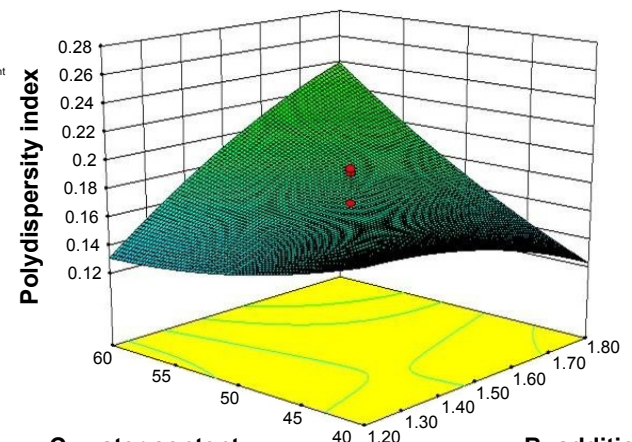

C: water content

G

\section{B}

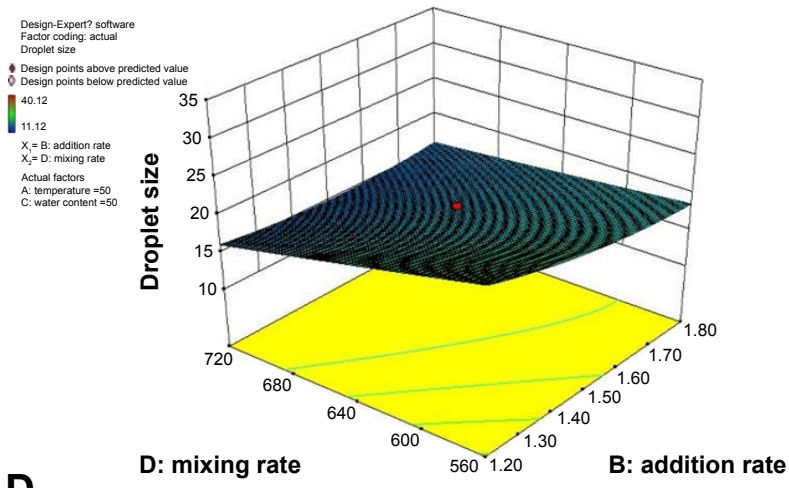

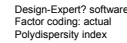

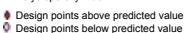

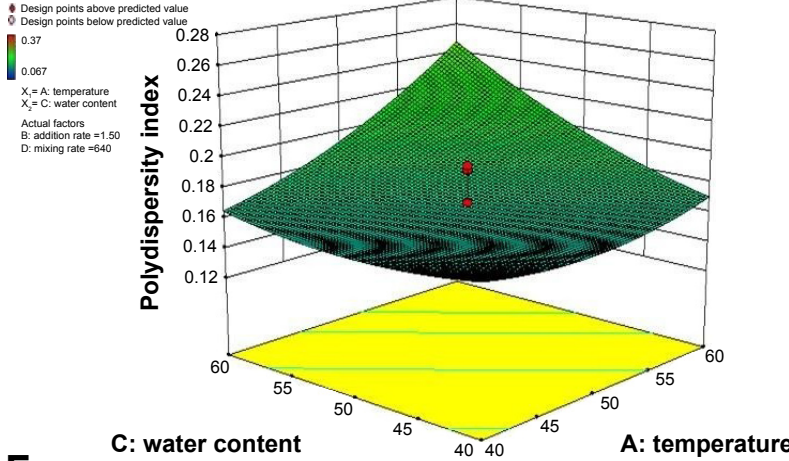

\section{$\mathbf{F}$}

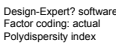

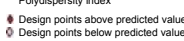
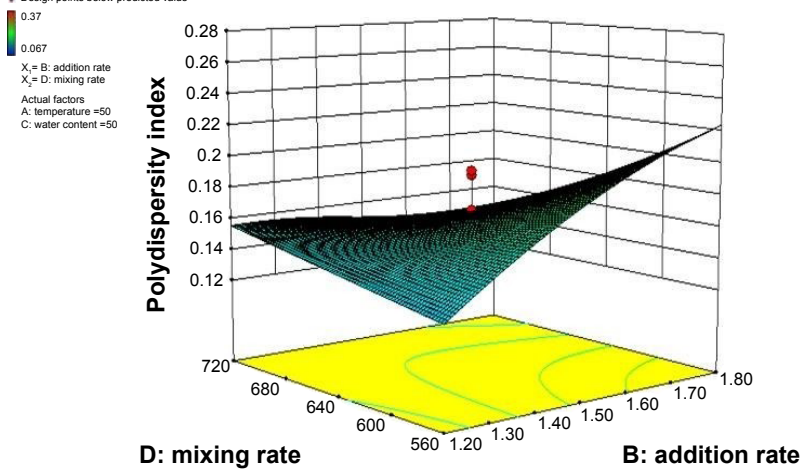

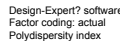

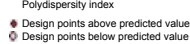

$\int_{0.067}^{0.37}$

$x_{1}=C$ : water content
$x_{2}=0$
D. mixing rate

$X_{2}=\mathrm{D}$ : mixing rate
Actual factors
A. temperature $=50$

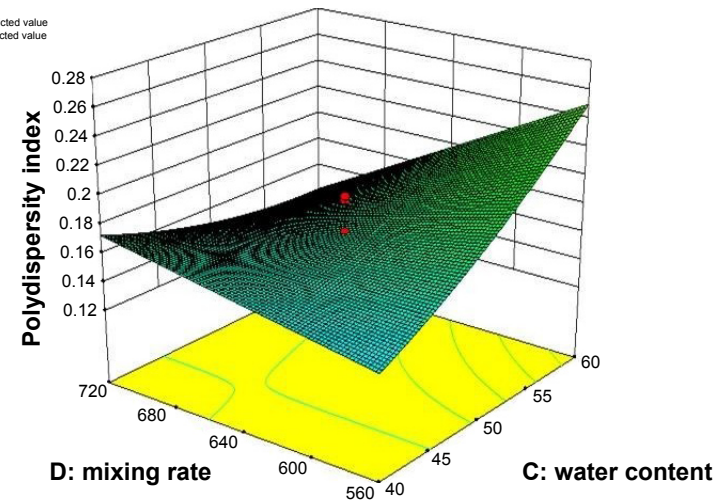

Figure 9 Response surface plots showing significant $(P<0.05)$ interaction effects.

Notes: Droplet size $(\mathbf{A}-\mathbf{C})$ and polydispersity index $(\mathbf{D}-\mathbf{G})$ as a function of temperature, addition rate, water content, and mixing rate. Variables not shown in each plot were kept constant at the center levels. 


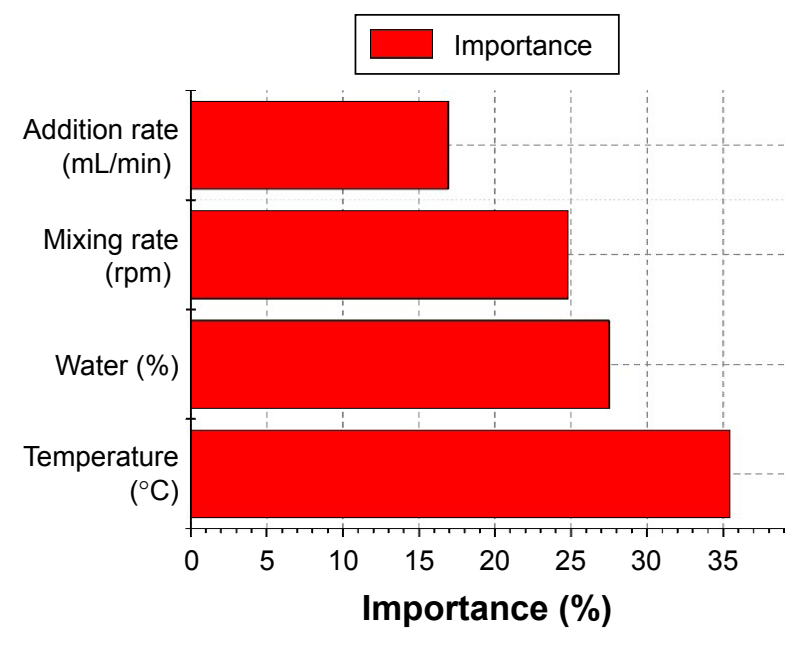

Figure 10 Importance of effective parameters on polydispersity index of nanoemulsion.

significant $(P<0.0001)$ effects on the PDI, except the interaction effect between temperature and water content, which had the least significant influence on PDI. Response surface graphs (Figure 9D-G) show that PDI was significantly affected by water content, temperature, mixing rate, and addition rate. Figure 10 indicates the importance of the effective parameters on the PDI value of nanoemulsions. Figure 9D shows that the PDI was hardly affected by the combined effect of water content and temperature. Figure $9 \mathrm{~F}$ and $\mathrm{G}$ shows that the combination of increased mixing rate and water content and the combination of increased mixing rate and addition rate widened the droplet-size distribution of the final emulsion. These results are well supported by previous reports ${ }^{18,24}$ on high-pressure emulsification processes. Conversely, Figure 9D shows that the combination of increased water content and addition rate narrow droplet-size distribution.

\section{Optimization of nanoemulsion formulation}

A nanoemulsion would be considered an optimum formulation if the applied optimization criteria resulted in smallest average droplet size and narrow PDI-value range in the presence of the lowest amount of emulsifier. ${ }^{22}$ Optimum processing conditions leading to the desired response goals were determined via superimposition of 3D response surfaces and contour plots. After analysis of various interaction effects from different angles and evaluation of optimization constraints, the optimum formulation with the most desirable properties was determined to be $41.49^{\circ} \mathrm{C}$ temperature, $1.74 \mathrm{~mL} / \mathrm{min}$ addition rate, $55.08 \%$ water content, and $720 \mathrm{rpm}$ mixing rate. Under optimum conditions, the corresponding predicted response value for average droplet size and PDI value were estimated to be $15.51 \mathrm{~nm}$ and 0.12 , respectively.

\section{Verification of the models}

Table 8 shows the comparison between the experimental and predicted data obtained from the CCD final reduced models. However, the adequacy of the final reduced models in predicting optimum response values was tested by performing the experiment under the recommended optimum conditions. $^{22}$ Three nanoemulsions were prepared according to the recommended optimal combination levels, and the corresponding values of average emulsion-droplet size and PDI were $15.8 \mathrm{~nm}$ and 0.108 , respectively. Experimental and predicted values were then compared to verify the validity of the response surface model. Intriguingly, response values from experimental data obtained from a freshly prepared emulsion sample were found to be slightly higher or slightly smaller than predicted, within $10 \%$ of predicted error. No significant differences were

Table 8 Experimental and predicted values for response variables obtained from CCD final reduced models

\begin{tabular}{|c|c|c|c|c|}
\hline \multirow{2}{*}{$\begin{array}{l}\text { Standard } \\
\text { order }\end{array}$} & \multicolumn{2}{|c|}{ Droplet size $(\mathrm{nm})$} & \multicolumn{2}{|l|}{ PDI } \\
\hline & $\begin{array}{l}\text { Actual } \\
\text { value }\end{array}$ & $\begin{array}{l}\text { Predicted } \\
\text { value }\end{array}$ & $\begin{array}{l}\text { Actual } \\
\text { value }\end{array}$ & $\begin{array}{l}\text { Predicted } \\
\text { value }\end{array}$ \\
\hline I & 12.47 & 15.43 & 0.12 & 0.13 \\
\hline 2 & 19.7 & 20.15 & 0.13 & 0.13 \\
\hline 3 & 11.52 & 10.8 & 0.14 & 0.15 \\
\hline 4 & 14.88 & 15.6 & 0.16 & 0.15 \\
\hline 5 & 31.67 & 31.38 & 0.11 & 0.13 \\
\hline 6 & 40.12 & 39.87 & 0.2 & 0.2 \\
\hline 7 & 23.89 & 24.91 & 0.3 & 0.3 \\
\hline 8 & 33.02 & 33.49 & 0.37 & 0.38 \\
\hline 9 & 18.24 & 17.15 & 0.24 & 0.22 \\
\hline 10 & 17.84 & 18.54 & 0.22 & 0.23 \\
\hline II & 15.8 & I7.77 & 0.11 & 0.11 \\
\hline 12 & 19.58 & 19.25 & 0.15 & 0.13 \\
\hline 13 & 15.98 & 16.98 & 0.067 & 0.078 \\
\hline 14 & 22.04 & 22.14 & 0.17 & 0.16 \\
\hline 15 & 16.84 & 15.77 & 0.12 & 0.12 \\
\hline 16 & 22.25 & 21.01 & 0.22 & 0.21 \\
\hline 17 & 23.41 & 22.07 & 0.18 & 0.16 \\
\hline 18 & 31.8 & 32.04 & 0.24 & 0.25 \\
\hline 19 & 25.99 & 24.76 & 0.11 & 0.096 \\
\hline 20 & 18.86 & 19 & 0.14 & 0.16 \\
\hline 21 & 11.12 & 9.34 & 0.16 & 0.16 \\
\hline 22 & 26.38 & 27.06 & 0.25 & 0.24 \\
\hline 23 & 24.92 & 23.29 & 0.22 & 0.21 \\
\hline 24 & 12.01 & 12.54 & 0.12 & 0.13 \\
\hline 25 & 17.03 & 17.63 & 0.19 & 0.17 \\
\hline 26 & 17.09 & 17.63 & 0.19 & 0.17 \\
\hline 27 & 19.85 & 17.63 & 0.16 & 0.17 \\
\hline 28 & 17.46 & 17.63 & 0.17 & 0.17 \\
\hline 29 & I7.01 & 17.63 & 0.17 & 0.17 \\
\hline 30 & 17.34 & 17.63 & 0.14 & 0.17 \\
\hline
\end{tabular}

Abbreviations: CCD, central composite design; PDI, polydispersity index. 


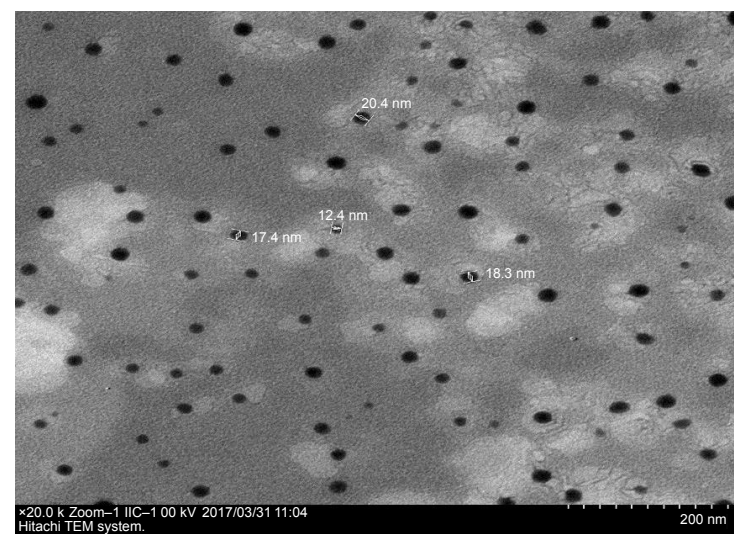

Figure I I Transmission electronic microscopy image of nanoemulsion containing 0.05 wt $\%$ of ceramide IIIB.

Note: Magnification 20,000x.

observed between predicted and actual values, indicating the suitability and sufficiency of the corresponding response-regression equations for relating the responses to independent variables.

\section{Transmission electron microscopy}

TEM (Figure 11) shows that nanoemulsion droplets (black spots on a white background) were spherical and uniform in size, with a large population of smaller droplets of $10-30 \mathrm{~nm}$, similar to the results of droplet-size measurement, which revealed that the experimental values for average emulsiondroplet size and PDI value were $15.80 \mathrm{~nm}$ and 0.108 , respectively.

\section{Conclusion}

Control of formulation and process parameters in the preparation of nanoemulsions containing ceramide IIIB is crucial for obtaining desirable attributes for effective transdermal delivery. This study showed that RSM was effectively applied to explain and predict the responses of particle size and PDI value of ceramide IIIB-loaded nanoemulsions. Due to the promising results of the present study, we have planned to carry out future studies that evaluate major factors influencing the encapsulation efficiency and stability of ceramide IIIB-containing nanoemulsions and the use of this formulation for dermal delivery of ceramide IIIB.

\section{Acknowledgment}

The authors wish to thank Core Facilities for Life Science, Jilin University, for their technical support.

\section{Disclosure}

The authors report no conflicts of interest in this work.

\section{References}

1. Denda M. Influence of dry environment on epidermal function. J Dermatol Sci. 2000;24(Suppl 1):S22-S28.

2. Lambers JW, Roehl EL, inventors; Gist-Brocades BV, assignee. Topical application of ceramides. United States patent US6001375. 1999 Dec 14

3. Sondari D, Haryono A, Harmami SB, Randy A. Influence of palmitoyl pentapeptide and ceramide III B on the droplet size of nanoemulsion. Proc SPIE Int Soc Opt Eng. 2010;7743:77430D.

4. Yukuyama MN, Ghisleni DD, Pinto TJ, Bou-Chacra NA. Nanoemulsion: process selection and application in cosmetics - a review. Int J Cosmet Sci. 2016;38(1):13-24.

5. Jafari SM, Paximada P, Mandala I, Assadpour E, Mehrnia MA. Encapsulation by nanoemulsions. In: Jafari SM, editor. Nanoencapsulation Technologies for the Food and Nutraceutical Industries. London: Elsevier; 2017:35-64.

6. Mason TG, Wilking JN, Meleson K, Chang CB, Graves SM. Nanoemulsions: formation, structure, and physical properties. J Phys Condens Matter. 2006;18(41):R635-R666.

7. Luisa Benassi GBaSS. In vitro testing of tensides employing monolayer cultures: a comparison with results of patch tests on human volunteers. Contact Dermatitis. 1999;40(1):38-44.

8. Moreno MA, Ballesteros MP, Frutos P. Lecithin-based oil-in-water microemulsions for parenteral use: pseudoternary phase diagrams, characterization and toxicity studies. J Pharm Sci. 2003;92(7): 1428-1437.

9. Thorsteinsson MV, Richter J, Lee AL, DePhillips P. 5-Dodecanoylaminofluorescein as a probe for the determination of critical micelle concentration of detergents using fluorescence anisotropy. Anal Biochem. 2005;340(2):220-225.

10. Bouchemal K, Briançon S, Perrier E, Fessi H. Nano-emulsion formulation using spontaneous emulsification: solvent, oil and surfactant optimisation. Int J Pharm. 2004;280(1-2):241-251.

11. Sonneville-Aubrun O, Simonnet JT, L'Alloret F. Nanoemulsions: a new vehicle for skincare products. Adv Colloid Interface Sci. 2004; 108-109:145-149.

12. Zhou H, Yue Y, Liu G, et al. Preparation and characterization of a lecithin nanoemulsion as a topical delivery system. Nanoscale Res Lett. 2009;5(1):224-230.

13. Tadros T, Izquierdo P, Esquena J, Solans C. Formation and stability of nano-emulsions. Adv Colloid Interface Sci. 2004;108-109:303-318.

14. Fernandez P, André V, Rieger J, Kühnle A. Nano-emulsion formation by emulsion phase inversion. Colloids Surf A Physicochem Eng Asp. 2004;251(1-3):53-58.

15. Ngan CL, Basri M, Lye FF, et al. Comparison of process parameter optimization using different designs in nanoemulsion-based formulation for transdermal delivery of fullerene. Int J Nanomedicine. 2014;9: 4375-4386.

16. Yolmeh M, Jafari SM. Applications of response surface methodology in the food industry processes. Food Bioprocess Technol. 2017;10(3): 413-433.

17. Azeem A, Rizwan M, Ahmad FJ, et al. Nanoemulsion components screening and selection: a technical note. AAPS PharmSciTech. 2009; 10(1):69-76.

18. Zainol S, Basri M, Basri HB, et al. Formulation optimization of a palm-based nanoemulsion system containing levodopa. Int J Mol Sci. 2012;13(10):13049-13064.

19. Taib SH, Gani SS, Rahman MZ, Basri M, Ismail A, Shamsudin R. Formulation and process optimizations of nano-cosmeceuticals containing purified swiftlet nest. RSC Adv. 2015;5(53):42322-42328.

20. Karadag A, Yang X, Ozcelik B, Huang Q. Optimization of preparation conditions for quercetin nanoemulsions using response surface methodology. J Agric Food Chem. 2013;61(9):2130-2139.

21. Musa SH, Basri M, Masoumi HR, et al. Formulation optimization of palm kernel oil esters nanoemulsion-loaded with chloramphenicol suitable for meningitis treatment. Colloids Surf B Biointerfaces. 2013; 112:113-119. 
22. Tang SY, Manickam S, Wei TK, Nashiru B. Formulation development and optimization of a novel Cremophore EL-based nanoemulsion using ultrasound cavitation. Ultrason Sonochem. 2012;19(2):330-345.

23. Hoeller S, Sperger A, Valenta C. Lecithin based nanoemulsions: a comparative study of the influence of non-ionic surfactants and the cationic phytosphingosine on physicochemical behaviour and skin permeation. Int J Pharm. 2009;370(1-2):181-186.

24. Yilmaz E, Borchert HH. Design of a phytosphingosine-containing, positively-charged nanoemulsion as a colloidal carrier system for dermal application of ceramides. Eur J Pharm Biopharm. 2005;60(1):91-98.

25. Yaron PN, Scott AJ, Reynolds PA, Mata JP, White JW. High internal phase emulsions under shear: co-surfactancy and shear stability. $J P h y$ Chem B. 2011;115(19):5775-5784.

26. Saberi AH, Fang Y, McClements DJ. Effect of glycerol on formation, stability, and properties of vitamin-E enriched nanoemulsions produced using spontaneous emulsification. J Colloid Interface Sci. 2013; 411:105-113.

27. Saberi AH, Fang Y, McClements DJ. Fabrication of vitamin E-enriched nanoemulsions by spontaneous emulsification: effect of propylene glycol and ethanol on formation, stability, and properties. Food Res Int. 2013;54(1):812-820.

28. Nagarajan R, Wang CC. Solution behavior of surfactants in ethylene glycol: probing the existence of a CMC and of micellar aggregates. J Colloid Interface Sci. 1996;178:471-482.

29. Aramaki K, Olsson U, Yamaguchi Y, Kunieda H. Effect of water-soluble alcohols on surfactant aggregation in the $\mathrm{C}_{12} \mathrm{EO}_{8}$ system. Langmuir. 1999;15(19):6226-6232.

30. Gradzielski M. Effect of the cosurfactant structure on the bending elasticity in nonionic oil-in-water microemulsions. Langmuir. 1998;14(21): 6037-6044

31. Yaghmur A, Aserin A, Garti N. Phase behavior of microemulsions based on food-grade nonionic surfactants: effect of polyols and short-chain alcohols. Colloids Surf A Physicochem Eng Asp. 2002;209(1):71-81.

32. Millard JW, Alvarez-Núñez FA, Yalkowsky SH. Solubilization by cosolvents: establishing useful constants for the log-linear model. Int $J$ Pharm. 2002;245(1-2):153-166.

33. Solè I, Maestro A, Gonzalez C, Solans C, Gutiérrez J. Optimization of nano-emulsion preparation by low-energy methods in an ionic surfactant system. Langmuir. 2006;22(20):8326-8332.

34. Shiao SY, Chhabra V, Patist A, et al. Chain length compatibility effects in mixed surfactant systems for technological applications. Adv Colloid Interface Sci. 1998;74(1-3):1-29.

35. Chantrapornchai W, Clydesdale FM, McClements DJ. Influence of relative refractive index on optical properties of emulsions. Food Res Int. 2001;34(9):827-835.

36. Wooster TJ, Golding M, Sanguansri P. Impact of oil type on nanoemulsion formation and Ostwald ripening stability. Langmuir. 2008; 24(22):12758-12765

37. Fluhr JW, Darlenski R, Surber C. Glycerol and the skin: holistic approach to its origin and functions. Br J Dermatol. 2008;159(1):23-34.

38. Fluhr JW, Mao-Qiang M, Brown BE, et al. Glycerol regulates stratum corneum hydration in sebaceous gland deficient (asebia) mice. J Invest Dermatol. 2003;120(5):728-737.

39. Rawlings A, Harding C, Watkinson A, Banks J, Ackerman C, Sabin R. The effect of glycerol and humidity on desmosome degradation in stratum corneum. Arch Dermatol Res. 1995;286(5):457-464.

40. Gloor M. How do dermatological vehicles influence the horny layer? Skin Pharmacol Physiol. 2004;17(6):267-273.

41. Fluhr JW, Gloor M, Lehmann L, Lazzerini S, Distante F, Berardesca E. Glycerol accelerates recovery of barrier function in vivo. Acta Derm Venereol. 1999;79(6):418-421.

42. Díaz-Blancas V, Medina DI, Padilla-Ortega E, Bortolini-Zavala R, Olvera-Romero M, Luna-Bárcenas G. Nanoemulsion formulations of fungicide tebuconazole for agricultural applications. Molecules. 2016; 21(10):E1271

43. Lawrence MJ, Rees GD. Microemulsion-based media as novel drug delivery systems. Adv Drug Deliv Rev. 2000;45(1):89-121.
44. Zhang H, Feng F, Li J, et al. Formulation of food-grade microemulsions with glycerol monolaurate: effects of short-chain alcohols, polyols, salts and nonionic surfactants. Eur Food Res Technol. 2007; 226(3):613-619.

45. Yu L, Li C, Xu J, Hao J, Sun D. Highly stable concentrated nanoemulsions by the phase inversion composition method at elevated temperature. Langmuir. 2012;28(41):14547-14552.

46. Borrin TR, Georges EL, Moraes ICF, Pinho SC. Curcumin-loaded nanoemulsions produced by the emulsion inversion point (EIP) method: an evaluation of process parameters and physico-chemical stability. J Food Eng. 2016;169:1-9.

47. Ajith S, Rakshit K. Studies of mixed surfactant microemulsion systems: Brij 35 with Tween 20 and sodium dodecyl sulfate. J Phys Chem. 1995; 99(40):14778-14783.

48. Prasert W, Gohtani S. Effect of temperature on low-energy nanoemulsification and phase behavior in water/polyoxyethylene sorbitan fatty acid ester (Tweens)/vegetable oil systems. J Food Eng. 2016;180: 101-109.

49. Yuan YQ, Zou XW, Xiong PF. Effects of temperature on the emulsification in surfactant-water-oil systems. Int J Mod Phys B. 2003; 17(14):2773-2780.

50. Magdassi S, Frank SG. Formation of oil-in-glycerol/water emulsions: effect of surfactant ethylene oxide content. J Dispers Sci Technol. 1990; 11(5):519-528.

51. Magdassi S, Frank SG. Formation of oil-in-glycerol/water emulsions. J Dispers Sci Technol. 1986;7(5):599-612.

52. McClements DJ, Rao J. Food-grade nanoemulsions: formulation, fabrication, properties, performance, biological fate, and potential toxicity. Crit Rev Food Sci Nutr. 2011;51(4):285-330.

53. Pey CM, Maestro A, Solé I, González C, Solans C, Gutiérrez JM. Optimization of nano-emulsions prepared by low-energy emulsification methods at constant temperature using a factorial design study. Colloids Surf A Physicochem Eng Asp. 2006;288(1-3):144-150.

54. Mayer S, Weiss J, McClements DJ. Vitamin E-enriched nanoemulsions formed by emulsion phase inversion: factors influencing droplet size and stability. J Colloid Interface Sci. 2013;402:122-130.

55. Saberi AH, Fang Y, McClements DJ. Fabrication of vitamin E-enriched nanoemulsions: factors affecting particle size using spontaneous emulsification. J Colloid Interface Sci. 2013;391:95-102.

56. Rezaee M, Basri M, Rahman RN, Salleh AB, Chaibakhsh N, Masoumi HR. A multivariate modeling for analysis of factors controlling the particle size and viscosity in palm kernel oil esters-based nanoemulsions. Ind Crops Prod. 2014;52:506-511.

57. Maali A, Mosavian MTH. Preparation and application of nanoemulsions in the last decade (2000-2010). J Dispers Sci Technol. 2013;34(1): $92-105$.

58. Li PH, Chiang BH. Process optimization and stability of D-limonenein-water nanoemulsions prepared by ultrasonic emulsification using response surface methodology. Ultrason Sonochem. 2012;19(1): 192-197.

59. Chanasattru W, Decker EA, McClements DJ. Modulation of thermal stability and heat-induced gelation of $\beta$-lactoglobulin by high glycerol and sorbitol levels. Food Chem. 2007;103(2):512-520.

60. Rezaee M, Basri M, Rahman RN, Salleh AB, Chaibakhsh N, Karjiban RA. Formulation development and optimization of palm kernel oil esters-based nanoemulsions containing sodium diclofenac. Int J Nanomedicine. 2014;9:539-548.

61. Mirhosseini H, Tan CP, Taherian AR, Boo HC. Modeling the physicochemical properties of orange beverage emulsion as function of main emulsion components using response surface methodology. Carbohydr Polym. 2009;75(3):512-520.

62. Yetilmezsoy K, Demirel S, Vanderbei RJ. Response surface modeling of $\mathrm{Pb}$ (II) removal from aqueous solution by Pistacia vera $\mathrm{L}$.: Box-Behnken experimental design. J Hazard Mater. 2009;171(1-3):551-562.

63. Khajeh $\mathrm{M}$. Response surface modelling of lead pre-concentration from food samples by miniaturised homogenous liquid-liquid solvent extraction: Box-Behnken design. Food Chem. 2011;129(4):1832-1838. 
64. Gutiérrez JM, González C, Maestro A, Solè I, Pey CM, Nolla J. Nanoemulsions: new applications and optimization of their preparation. Curr Opin Colloid Interface Sci. 2008;13(4):245-251.

65. Cho HJ, Lee DW, Marasini N, et al. Optimization of self-microemulsifying drug delivery system for telmisartan using Box-Behnken design and desirability function. J Pharm Pharmacol. 2013;65(10):1440-1450.

66. Kentish S, Wooster TJ, Ashokkumar M, Balachandran S, Mawson R, Simons L. The use of ultrasonics for nanoemulsion preparation. Innov Food Sci Emerg Technol. 2008;9(2):170-175.
67. Jafari SM, He Y, Bhandari B. Effectiveness of encapsulating biopolymers to produce sub-micron emulsions by high energy emulsification techniques. Food Res Int. 2007;40(7):862-873.

68. Jafari SM, Assadpoor E, He Y, Bhandari B. Re-coalescence of emulsion droplets during high-energy emulsification. Food Hydrocoll. 2008; 22(7):1191-1202. 


\section{Supplementary materials}

A

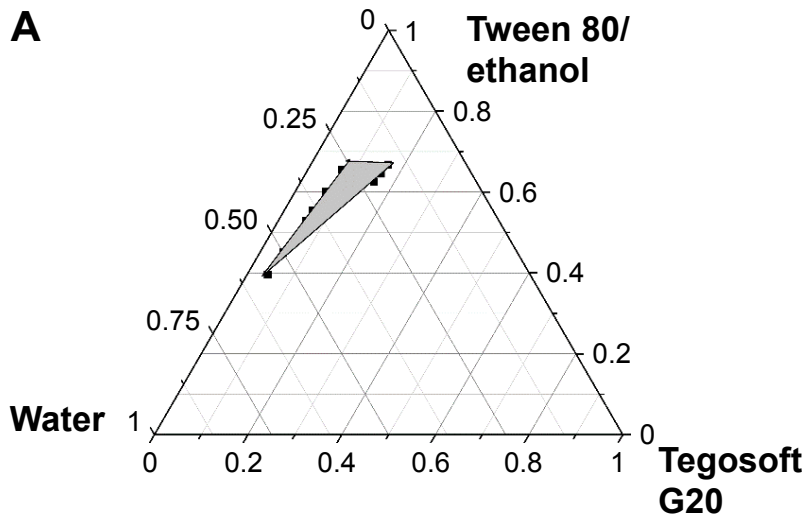

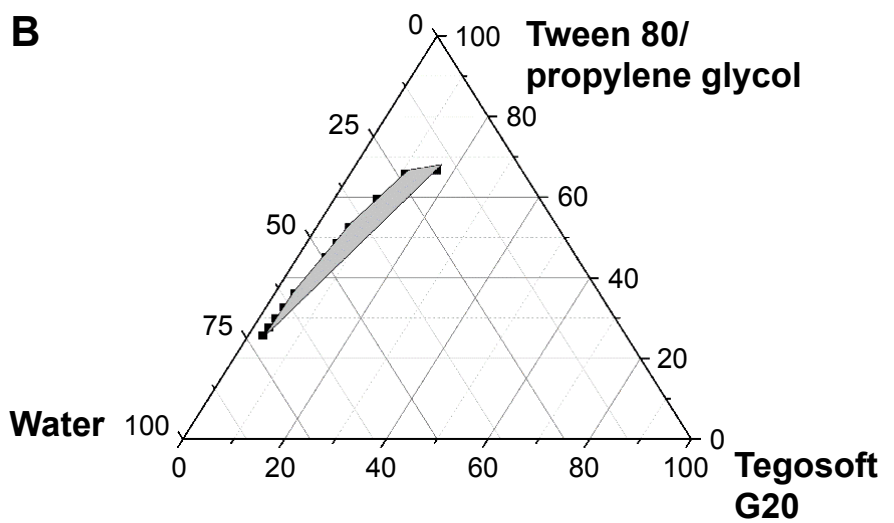

B G20

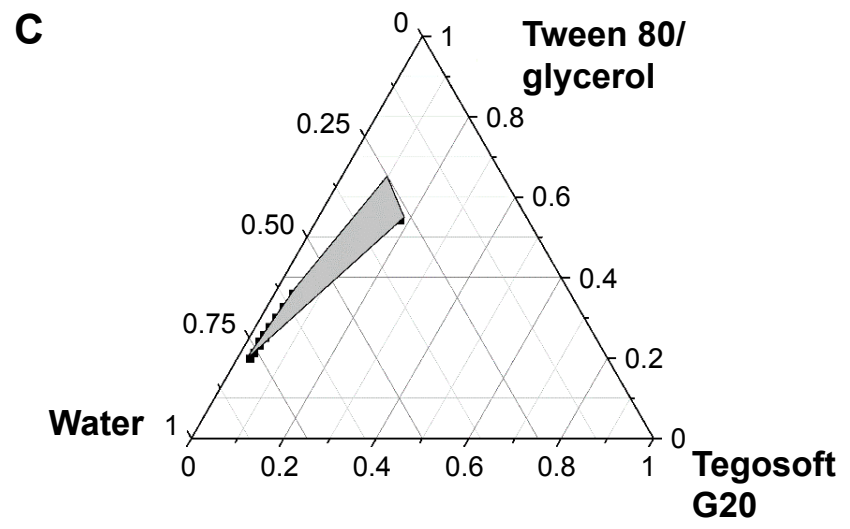

Figure SI Pseudoternary phase diagrams of nanoemulsion composed of Tegosoft G20, Tween 80, water, and different cosurfactants. Notes: (A) Ethanol; (B) propylene glycol; (C) glycerol at $\mathrm{S}_{\text {mix }}$ ratio of I:I.

Abbreviation: $\mathrm{S}_{\text {mix }}$, surfactant:cosurfactant. 

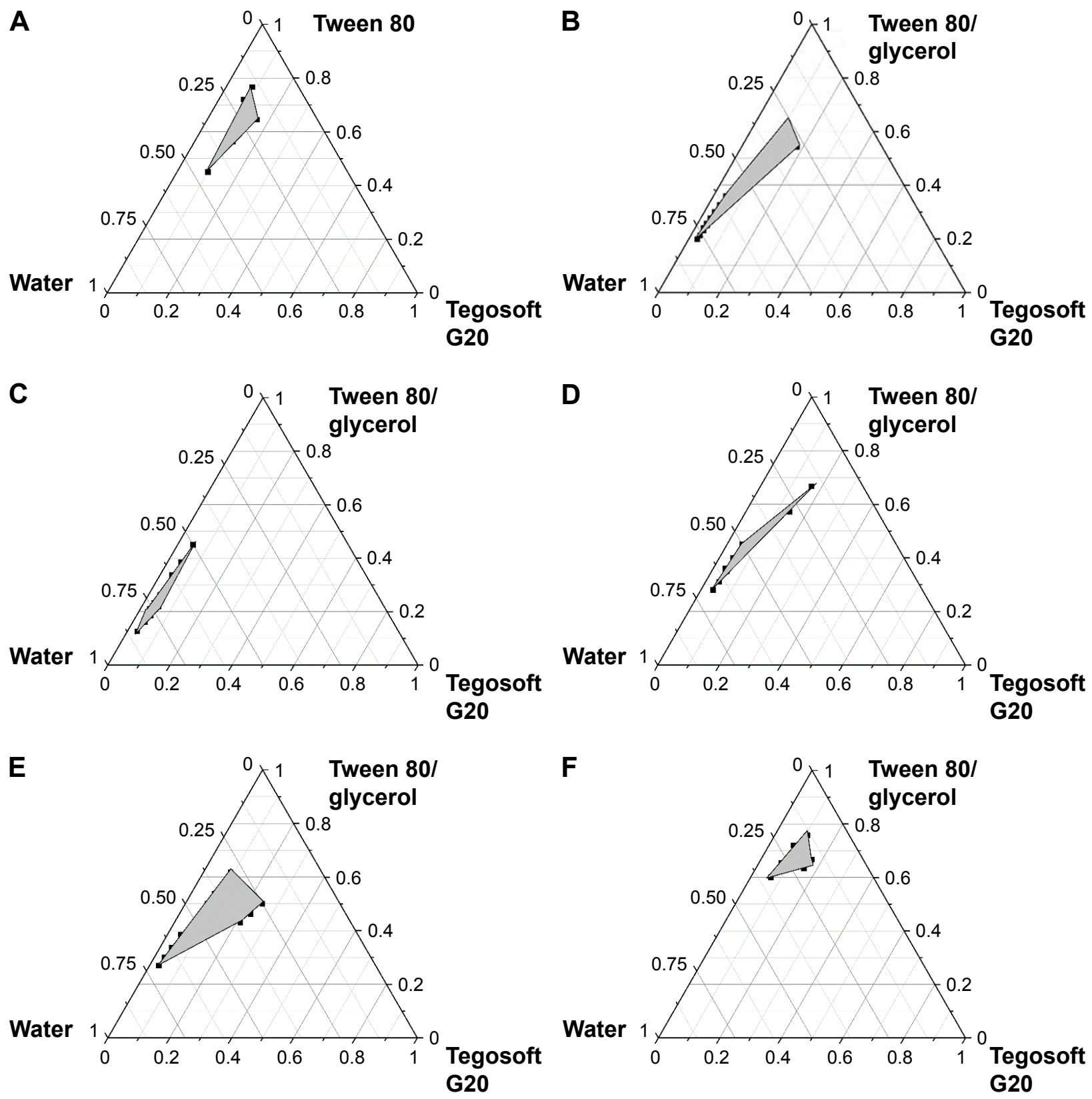

Figure S2 Pseudoternary phase diagrams indicating oil-in-water nanoemulsion regions.

Notes: Tegosoft G20 (oil), water, Tween 80 (surfactant), and glycerol (cosurfactant) at different $\mathrm{S}_{\text {mix }}$ ratios: (A) I:0; (B) I:1; (C) I:2; (D) I:3; (E) 2:I; (F) 3:I. Abbreviation: $\mathrm{S}_{\text {mix }}$, surfactant:cosurfactant.

\section{Publish your work in this journal}

The International Journal of Nanomedicine is an international, peerreviewed journal focusing on the application of nanotechnology in diagnostics, therapeutics, and drug delivery systems throughou the biomedical field. This journal is indexed on PubMed Central, MedLine, CAS, SciSearch ${ }^{\circledR}$, Current Contents ${ }^{\circledR} /$ Clinical Medicine,
Journal Citation Reports/Science Edition, EMBase, Scopus and the Elsevier Bibliographic databases. The manuscript management system is completely online and includes a very quick and fair peer-review system, which is all easy to use. Visit http://www.dovepress.com/ testimonials.php to read real quotes from published authors. 